\title{
WHAT DOES IT MEAN TO BE A "PARENT"? THE CLAIMS OF BIOLOGY AS THE BASIS FOR PARENTAL RIGHTS
}

\author{
John LAWRENCE HiLL*
}

\begin{abstract}
Modern technology has wreaked havoc on conventional and legal notions of parenthood. For example, the traditional legal presumption granting parental rights to a child's biological mother seems at least questionable when the biological mother differs from the intended mother. As a result, courts employing traditional constitutional and family law doctrines have not adequately sorted out the claims of biological, gestational, and intended parents. In this Article, Professor Hill argues that the claims of those who first intend to have a child should prevail over those who assert parental rights on the basis of a biological or gestational relation. Such a view, he argues, is consistent with existing case law on the constitutional rights to procreation and privacy and supported by moral theory and modern scientific evidence.
\end{abstract}

\section{INTRODUCTION}

In 1799, the first reported use of artificial insemination took place. ${ }^{1}$ With this event, the once-insoluble link between coitus and procreation was severed. However, while sporadic experimentation with artificial insemination continued through the first third of the twentieth century, ${ }^{2}$ it was not until the 1930s and 1940s that artificial insemination by donor (AID) began to be recognized and employed on a widescale basis as a response to the problem of male infertility. ${ }^{3}$ Within the past two de-

* Assistant Professor of Law, Western State University at Irvine. B.A. (Philosophy), 1982, Northern Illinois University; M.A. (Philosophy), 1985, Northern Mllinois University; J.D., 1988, Ph.D. (Philosophy), 1989, Georgetown University. I wish to thank my former colleagues at IIT-Chicago Kent Law School for their support in this project. Special thanks go to Professor Sheldon Nahmod for his kind assistance and guidance.

1 U.S. Cong. Office of Technology Assessment, Infertility: Medical and Social Choices 36 (1988) [hereinafter OTA, Infertility]. Artificial insemination is a process by which sperm from a donor is injected, usually via syringe, into the vaginal opening. Artificial insemination consists of two varieties: artificial insemination by donor (AID) and by husband (AIH). AID is used where a woman's husband is sterile or where a woman wishes to avoid sexual intercourse. Id. at 126-28. AIH is used where normal coital methods of procreation are, for a variety of reasons, ineffective. Id.

2 In the 1860s, for example, Dr. J. Marion Sims experimented with AID but later renounced the work as immoral. Note, Legal Recognition of Surrogate Gestation, 7 Women's Rts. L. Rep. 107, 119 n.88 (1982).

3 It is estimated that anywhere from 6000 to 10,000 births a year result from AID. See Curie-Cohen, Luttrell \& Shapiro, Current Practice in Artificial Insemination by Donor in the United States, $300 \mathrm{New}$ Eng. J. Med. 585, 588 (1979). One estimate places the number at 20,000 a year. See Note, supra note 2, at 119 . Approximately 250,000 Americans now living were born through the use of AID or AIH. Keane, Legal Problems of Surrogate Motherhood, 1980 S. Ill. U.L. Rev. 147, 148. See generally J. Fletcher, Morals and Medicine 101-16 (1954) 
cades, the process of procreation has been fragmented further by the development of a number of techniques, most notably in-vitro fertilization, which separate the conceptive and gestational phases of reproduction. ${ }^{4}$ Thus, the genetic and gestational mothers of a child are no longer necessarily the same individual. ${ }^{5}$ In this manner, science has distilled the various phases of procreation - coitus, conception, and gestation-into their component parts, wreaking havoc on our prevailing conceptions of parenthood.

This is not to suggest that parenthood always has been recognized as being coextensive with the biological relationship. While legal adoption is a statutory creation not existing at common law, ${ }^{6}$ in practice it undoubtedly has taken place from time immemorial. ${ }^{7}$ Thus, a strong social tradition recognizes the purely social and psychological dimensions of parenting, even where these occur in the absence of biological ties. Yet even with adoption, adoptive parents may acquire parental status with respect to a particular child only after termination of the parental rights of the child's biological parents, particularly those of the natural mother. ${ }^{8}$ With the new reproductive technologies and arrangements, ${ }^{9}$

(discussing and defending artificial insemination).

${ }^{4}$ In-vitro fertilization (IVF) involves the removal of mature oocytes (female germ cells) through a surgical procedure known as laparoscopy or a nonsurgical procedure such as uitrasound-guided oocyte retrieval. Once removed, the ova are combined with sperm in the laboratory. After fertilization, a number of preembryos, generally at the two to 16 cell stage, are transferred to the uterus of the woman who will bear the child. OTA, Infertility, supra note 1, at 123.

5 The woman to whose uterus the fertilized preembryo is transferred need not be the original egg donor. The first child born in the U.S. of gestational surrogacy-a surrogate arrangement where the surrogate gestates but does not conceive the child-took place in 1985. Id. at 36.

6 See Smith v. Org. of Foster Families, 431 U.S. 816, 845-46 (1977).

7 See I. Sloan, The Law of Adoption and Surrogate Parenting 5-10 (1988).

8 The "presumption of biology" serves as an irrebuttable legal presumption that the birth mother of the child is its legal mother and that adoption can take place only consequent to a termination of the parental rights of the birth mother. See Andrews, Surrogate Motherhood: Should the Adoption Model Apply?, 7 Children's Legal Rts. J. 13, 14-16 (1986) (discussing adoption laws as applied to surrogacy); notes 74-89 and accompanying text infra (discussing presumption of biology).

9 I distinguish the reproductive "technologies" from "arrangements" to highlight that, while many of these procedures such as AID and IVF involve some use of technology, surrogate parenting involves a social and legal, rather than a technological, innovation. While surrogacy typically uses AID to impregnate the surrogate with the sperm of the intended father or a third-party donor, the characteristic feature of surrogacy is the social arrangement whereby a woman agrees to conceive (in most, but not all cases), to carry, and to relinquish the child upon birth. See Brophy, A Surrogate Mother Contract to Bear a Child, 20 J. Fam. L. 263, 268-91 (1981-82) (explaining surrogate arrangement); see also Hill, The Case for Enforcement of the Surrogate Contract, 8 Pol. \& Life Sci. 147, 150-57 (1990) (discussing policy issues surrounding surrogacy); Suh, Surrogate Motherhood: An Argument for Denial of Specific Performance, 22 Colum. J.L. \& Soc. Probs. 357, 362-71 (1989) (arguing that bonding process experienced during pregnancy gives woman inalienable right as parent). 
however, a more fundamental question arises: where various parties have made distinct contributions to the procreative process, who should be recognized as the parents of the child?

We now live in an era where a child may have as many as five different "parents." These include a sperm donor, an egg donor, a surrogate or gestational host, and two nonbiologically related individuals who intend to raise the child. Indeed, the process of procreation itself has become so fragmented by the variety and combinations of collaborative-reproductive methods that there are a total of sixteen different reproductive combinations, in addition to traditional conception and childbirth. This total is the product of varying the source of the male gametes (whether by husband or third-party sperm donor), the source of the female gametes (whether by wife or third-party egg donor), the location of fertilization (whether in the wife, the laboratory, or the surrogate host), and the site of gestation (either in the wife or the surrogate). ${ }^{\text {o }}$

The importance of parental status, and the accompanying controversy where the identity of the parent is not determined, can be observed in a number of currently debated issues concerning collaborative repro-

\begin{tabular}{|c|c|c|c|c|c|}
\hline \multirow[t]{2}{*}{1} & \multicolumn{5}{|c|}{ ALTERNATIVE REPRODUCTIVE METHODS } \\
\hline & \multicolumn{2}{|c|}{$\begin{array}{l}\text { Source of } \\
\text { gametes }\end{array}$} & \multirow{2}{*}{$\begin{array}{c}\text { Site of } \\
\text { fertilization }\end{array}$} & \multirow[t]{2}{*}{$\begin{array}{c}\text { Site of } \\
\text { pregnancy }\end{array}$} & \multirow[t]{2}{*}{ Notes } \\
\hline & Male & Female & & & \\
\hline 1 & $\mathbf{H}$ & $\mathbf{W}$ & $\mathbf{w}$ & $\mathbf{w}$ & Customary, AIH \\
\hline 2 & $\mathbf{s}$ & W & W & W & AID \\
\hline 3 & $\mathbf{H}$ & W & $\mathbf{L}$ & W & IVF \\
\hline 4 & $\mathbf{s}$ & W & $\mathbf{L}$ & W & IVF with donated sperm \\
\hline 5 & $\mathbf{H}$ & $\mathbf{s}$ & $\mathbf{L}$ & W & IVF with donated egg \\
\hline 6 & $\mathbf{S}$ & $\mathbf{S}$ & $\mathbf{L}$ & $\mathbf{W}$ & $\begin{array}{l}\text { IVF with both gametes donated (or donated } \\
\text { embryo) }\end{array}$ \\
\hline 7 & $\mathbf{H}$ & $\mathbf{s}$ & $\mathbf{s}$ & W & $\begin{array}{l}\text { AIH with donor woman plus uterine lavage } \\
\text { (semi-donated embryo) }\end{array}$ \\
\hline 8 & $\mathbf{S}$ & $\mathbf{S}$ & $\mathbf{S}$ & $\mathbf{W}$ & $\begin{array}{l}\text { AID with donor woman plus uterine lavage } \\
\text { (donated embryo) }\end{array}$ \\
\hline 9 & $\mathbf{H}$ & W & W & $\mathbf{S}$ & ) \\
\hline 10 & $\mathbf{S}$ & w & W & $\mathbf{s}$ & \\
\hline 11 & $\mathbf{H}$ & $\mathbf{W}$ & $\mathbf{L}$ & $\mathbf{S}$ & \\
\hline 12 & $\mathbf{S}$ & $\mathbf{W}$ & $\mathbf{L}$ & $\mathbf{S}$ & Surrogate \\
\hline 13 & $\mathbf{H}$ & $\mathbf{s}$ & $\mathbf{L}$ & $\mathbf{s}$ & Motherhood \\
\hline 14 & $\mathbf{S}$ & $\mathbf{S}$ & $\mathbf{L}$ & $\mathbf{S}$ & \\
\hline 15 & $\mathbf{H}$ & $\mathbf{S}$ & $\mathbf{S}$ & $\mathbf{s}$ & \\
\hline $16^{*}$ & $\mathbf{S}$ & $\mathbf{S}$ & $\mathbf{S}$ & $\mathbf{S}$ & \\
\hline
\end{tabular}

$\mathbf{H}=$ Husband; $\mathbf{W}=$ Wife; $\mathbf{S}=$ Third-party substitute, or surrogate;

$\mathrm{L}=$ Laboratory

* Planned procreation for placement; traditional adoption is not part of the schematic.

Chart developed by William B. Weil, Jr. and LeRoy Walters.

Walters, Editor's Introduction, 10 J. Med. \& Phil. 209, 210 (1985) (although in theory 24 permutations are possible, only 16 actually would occur because of various overlaps). 
duction. For example, one may question whether surrogate-parenting arrangements constitute a highly contrived form of baby-selling. ${ }^{11}$ The answer depends upon which parties to the procreative process are deemed to be the "parents" of the child at birth. If the intended parents ${ }^{12}$ are recognized as the parents of the child, then it is difficult to see how they could be guilty of buying their own baby. Similarly, if the surrogate is deemed not to be the mother of the child, she cannot, as a logical matter, be culpable for baby-selling. ${ }^{13}$

Determination of parental status also may have great significance in deciding who possesses the right of procreation. Arguably, only a "parent" can exercise the right of procreation ${ }^{14}$ with respect to any particular child. Indeed, it is exactly this proposition that this Article defends. ${ }^{15}$ It follows that the application of the constitutional right of procreation depends upon an antecedent definitional conclusion regarding the meaning of parenthood. This determination will have fundamental significance where the genetic progenitors, the gestational host, and the intended parents (where the intended parents are not also the genetic parents) all claim parental status based on their respective roles in the procreative process. ${ }^{16}$

Finally, competing conceptions of the rights of the biological parents, and most particularly the gestational host, animate the stormy debate concerning the enforceability of the surrogate contract. Where the

11 "Baby-selling" laws make it a criminal offense to exchange money or other material consideration for the promise of a parent of the child to relinquish custody and parental rights in the child. See Katz, Surrogate Motherhood and the Baby-Selling Laws, 20 Colum. J. L. \& Soc. Probs. 1, 8-9 (1986).

12 I use the term "intended parents" here to describe the person or couple who initially intended to raise the child. Three conditions must be met for persons to be considered intended parents: (1) the intended parents must plan to have a child before the conception of the child; (2) they must take morally permissible measures, not limited to biological procreation, to bring a child into the world; and (3) they must meet certain minimally adequate conditions to be able to raise and care for the child. This last requirement embodies the condition that parents obtain the "constructive consent of the child." See text accompanying notes 171-72 infra.

13 This outcome would be a departure from the $B a b y M$ court, which stated that the egg donor/gestational host was "the natural mother inappropriately called the 'surrogate mother." " In re Baby M., 109 N.J. 396, 411, 537 A.2d 1227, 1234 (1988). Having decided the issue of motherhood, the court went on to state that the surrogacy contract was "the sale of a child, or, at the very least, the sale of a mother's right to her child." Id. at 437-38, $537 \mathrm{~A} .2 \mathrm{~d}$ at 1248.

14 See Skinner v. Oklahoma, 316 U.S. 535, 541 (1942) (currently viewed as establishing right of procreation by holding involuntary sterilization statute unconstitutional); note 67 and accompanying text infra (discussing decisions of $B a b y M$ court regarding parenthood and right of procreation); see also text accompanying notes 129-30 infra (biological connection offers unique opportunity for parental relationship).

15 See notes 61-62 and accompanying text infra.

16 See Allen, Privacy, Surrogacy and the Baby $M$ Case, 76 Geo. L.J. 1759, 1774-81 (1988) (discussing four models for privacy-right attribution). 
connotations associated with motherhood invariably are linked with the role of the birth mother, the prospect of compelling her to relinquish the child takes on the proportions of a crime against nature. However, where parental status is deemed to attach to the persons who have sought, by whatever means they could marshal, to cause a child to be born so that they could raise it and care for it-in short, where parental status is viewed as distinct from biological consanguinity-enforcement of the surrogate contract will be viewed as a necessary prerequisite to achieving justice.

This Article attempts to arrive at a conception of parenthood which settles conflicting claims to parental status posed by the genetic parents, the gestational host, and the intended parents of the child. Part I begins by posing the paradigmatic procreative scenario in which such conflicting claims to parental status will arise. This Part then evaluates a number of definitional considerations relating to the use of the term "parent," arguing that appeals to traditional definitions are of little use in answering what is essentially a normative question: who should be considered the parent in collaborative-reproduction arrangements? It also argues that, while we lack a concept of parenthood sufficiently definite to resolve modern controversies about who is the parent, we nevertheless have a working legal definition of parental rights that can help reveal what is at stake in the controversy. Thus, this Part examines the rights which attach to persons legally recognized as parents, as demonstrated by the parental-rights doctrine.

Whereas Part I concludes by focusing on what rights parents have, Part II turns to the central question of who, legally, may be a parent. Seemingly uncontroversial claims to parental rights can be made by the procreators of a child. Indeed, the Constitution has long recognized that parental status inures to procreators. ${ }^{17}$ A problem arises, however, in attempting to define who counts as a procreator. Under existing legal doctrine, although a biological connection between adult and child is not always a sufficient condition to establish procreator status, it is virtually a necessary condition, at least in the ascription of maternal rights. Yet as the remainder of Part II demonstrates, to link biology and procreation so closely is to confuse the right of procreation with the right of privacy. In fact these rights are distinct, and recognition of this distinction suggests that intended parents ${ }^{18}$ have a respectable claim to being procreators. Part II concludes that the legal right to procreation can be read to support parental-rights claims of intended parents over the claims of biologi-

17 See, e.g., Skinner, 316 U.S. at 541 (procreation is basic, fundamental civil right); Baby $M, 109$ N.J. at $449-52,537$ A.2d at 1254-55 (considering only procreators when discussing parental rights).

18 See note 12 supra. 
cal parents, where the two types of claims conflict.

Part III looks beyond the law to determine if empirical evidence and moral arguments favor the right of biological progenitors to be accorded primary legal recognition as the parents of a child. More specifically, Part III assesses the claims that a person possesses a parental right in a child by virtue of the following: the genetic relationship which exists between them, the efforts inherent in the gestational relationship, the "bond" which develops between the birth mother and the child as a result of the gestational relationship, and a variety of predicted psychological harms to mother and child resulting from their separation. This Part also evaluates the general claim that it is in the child's best interests to be placed with its natural parents. In addition, Part III investigates a number of extrinsic social and moral arguments focusing not on the rights of particular parties per se, but on a variety of consequences which may follow the adoption of a definition of parent which would favor one group over another. This Part argues that many of the claims posed in defense of the priority of the genetic progenitors or gestational host carry little moral weight and that the case for the primacy of the rights of biological parents is considerably weaker than it might first appear.

Finally, Part IV sketches three arguments favoring the claims of the intended parents-even where they lack any biological ties with the child born of the procreative relationship. This Part argues that, under an "intentional" view of parenting, the claims of the intended parents outweigh those of the gestational host. Thus, the parental rights of the intended parents should be legally recognized from the time of conception.

I

What Does It Mean to Be A "Parent"?

\section{A. The Problem}

Imagine the following scenario. A married couple wishes to have a child. Unfortunately, both spouses are infertile. As the result of testicular cancer, the husband physically is incapable of producing sperm. Similarly, due to a condition known as endometriosis, the wife is incapable of producing ova. The condition also has affected her capacity to bring to term a previously conceived embryo. ${ }^{19}$ In essence, the couple lacks the biological ability to produce a child genetically or gestationally.

Nevertheless, after repeated unsuccessful attempts at adoption, the couple decides to "have a child of its own." They proceed by contacting

19 See OTA, Infertility, supra note 1, at 65-66 (discussing endometriosis and its effects on women's capacity both to produce ova and to bring fetus to term); id. at 72-73 (discussing effects of cancer on male and female fertility). 
a facility which collects and stores donor sperm for artificial insemination. The couple carefully reviews the records indicating a number of general characteristics of the prospective donor including height, weight, age, race, eye color, hair color, occupation, talents, and hobbies. They choose the sperm of an individual whose general physical appearance and professional biography most closely approximate that of the husband. Next, the couple contacts one of the recently established ova banks. They choose ova contributed by a woman with physical and intellectual attributes strikingly similar to that of the wife. ${ }^{20}$

The couple then selects a suitable woman who has expressed an interest in assisting an infertile couple to bring a child into the world. The surrogate is to be paid $\$ 10,000$ and, to increase the probability of pregnancy, agrees to have three preembryos surgically implanted, after which she will carry and bear the child, relinquishing the child to the couple upon birth. Through the process of in vitro fertilization, the sperm and ova of the two anonymous donors are united. Three days after conception, the preembryos are transferred to the surrogate who carries one of them to term and bears a healthy baby girl. Shortly after birth, the surrogate turns the child over to the commissioning couple. The new "parents" have "brought a child into the world."

But who are the "parents" in the preceding scenario? Should the answer depend upon whether the surrogate willingly relinquishes her claim to the child? Indeed, who is more like a parent here? Are the husband and wife, who carefully and intentionally orchestrated the procreational act, bringing together all the necessary components with the intention of creating a unique individual whom they intend to raise as their own, the parents? Or is the gestational host, who bore the physical burden of pregnancy and the pain of labor, more properly the "mother" of the child? Or should the genetic parents-the anonymous donors-if they knew of the existence of the child, take legal priority as its parents? Thus we are led to inquire: what relevance do the various intentional, genetic, and gestational components of procreation have for the concept of parenthood? The answer depends upon our definition of "parent."

\section{B. The Limits of Definition}

The use of definitions in any empirical area poses a curious dilemma. ${ }^{21}$ We seek to define a particular concept so that, among other

20 While the couple would have preferred an in-depth psychological and intellectual sketch of each of the two donors, this is not yet available. Consequently, they construct a general psychological picture of each donor based upon the other information present in the biographies.

21 I classify definitions into the "analytic" and the "empirical." Analytic definitions are those which are true as a matter of logic. The definition is "contained" within the concept. 
reasons, we can accurately distinguish uncertain or borderline examples of that concept from counterexamples or instances falling outside of the scope of that concept. In the process of arriving at a definition, we must make antecedent determinations of the scope of the concept. In other words, if we could be certain when a particular object, $X$, falls within the operational scope of a concept, $F$, the need to define $F$ would be eliminated, or at least greatly mitigated. Thus, in arriving at a definition of any concept, we must come to some preliminary conclusions about which particular examples fall within the definitional scope of that concept. In short, we seek definition in order to distinguish instances of a concept from noninstances. But we must make these distinctions prior to the definition, in effect deciding in advance whether certain instances fall within the scope of the concept.

In attempting to define the term "parent," for example, we must make certain assessments about uncertain cases. Is a person who raises a child, but who is not biologically related to the child, truly a "parent"? Is an egg donor who does not carry the child to term the "mother" of the child? In deciding these uncertain cases, we implicitly appeal to some preanalytic concept of parenthood, as if presupposing the definition. ${ }^{22}$ Yet the entire reason for seeking a definition in the first place is to permit us to know whether an egg donor, for example, is a "mother." Thus, the entire process is circular.

It might appear that we should surmount this obstacle simply by stipulating a definition of parenthood. Thus, we could provide, almost by fiat, that the term "parent" is to be understood as designating a biological parent of the child, or a party who actually raises the child, or some other party. This would provide order where it formerly was ab-

But see D. O'Connor \& B. Carr, Introduction to the Theory of Knowledge 145-63 (1982) (questioning existence of separate category of analytic truths). So, for example, according to the analytic definition, a triangle is a three-sided closed-plane polygon. To know what a triangle is, is to know whether or not any particular object is in fact a triangle.

Empirical definitions, by contrast, have uncertain boundaries. The concept "chair," for example, appears to have no necessary and sufficient conditions for application. It is uncertain how many legs a chair must have. Similarly, by analyzing the concept of a chair, we cannot determine at what precise width a chair becomes a sofa. Parenthood is an empirical concept. By analyzing the term we cannot arrive at a set of necessary and sufficient limiting criteria for its application.

22 Concerns such as these led Plato and his followers to posit a realm of the Forms; a nonspatial, nontemporal domain in which the perfect Forms of every particular object exist. See Plato, Paramenides, in The Dialogues of Plato (B. Jowett trans. 4th ed. 1953). Each concept is, in some sense, a mental representation of this transcendental Form. See id. By remembering these Forms we gain a kind of a priori knowledge. Aristotle modified this thesis to exclude the notion of a transcendental realm in which the Forms exist but retained the notion of universals as a representation of the essence of each concept. See Aristotle, The Metaphysics, in The Works of Aristotle (W. Ross ed. 1949); Woozley, Universals, in 8 The Encyclopedia of Philosophy 194 (P. Edwards ed. 1967). 
sent since whichever definition of parenthood is chosen, all parties will have prospective notice of the governing definition and will be aware of their corresponding status in light of the definition.

There is, however, a significant problem with this approach. If the definition which we stipulate does not comport with the way in which the term actually is used, the definition may provide theoretical order, but only at the price of alienating the term from its traditional use. For parenthood to continue to be recognized as perhaps the most fundamental social relationship in our culture, carrying with it the basis for a number of basic human rights with which it has historically been associated, ${ }^{23}$ a continuity of core meaning must be maintained. To stipulate a meaning for "parenthood" which is fundamentally distinct from the traditional way in which the term is used is to open the door to a changed, and perhaps diminished, social significance for parenthood as an institution. Moreover, the stipulative definition is, in a significant sense, arbitrary. It thus can be challenged as merely asserting by fiat that which it is supposed to answer.

Rather than providing a stipulative definition, we could seek what Professor Copi calls a "lexical" definition. ${ }^{24}$ This is a definition of a term reflecting the way people use it in common parlance. The common use of the term, however, may be ambiguous, lacking clear boundaries, and may be equivocal, having conflicting meanings. Moreover, common usage may manifest certain "gaps" in meaning. In the case of the term "parent," for example, the very fact that common usage is unclear in a number of novel situations has motivated this entire definitional search. Consequently, we need something more than an appeal to the lexical use of the term "parent."

Perhaps what is required is what Copi dubs a "precising" definition. ${ }^{25}$ A precising definition is, in effect, a hybrid of the stipulative and lexical definitions. It is used in an effort to remain as faithful as possible to the common usage of the term while simultaneously stipulating its scope. ${ }^{26}$ In ambiguous cases, the precising definition sets forth a meaning

23 See notes 44-51 and accompanying text infra (discussing constitutional rights accorded by virtue of parental status).

24 Professor Copi distinguishes five types of definitions: stipulative, lexical, precising, theoretical, and persuasive. Each has a different function and can result in disparate meanings for the same term. The primary logical distinction between a stipulative definition and a lexical definition is that a truth value can be assigned to the latter, but not to the former. In other words, it either is or is not true that a certain term is used in common parlance in a particular way. Conversely, the stipulative meaning need not conform to common usage at all. See $I$. Copi, Introduction to Logic 140-47 (7th ed. 1986).

25 See id. at 144-45.

26 Thus, there is only a partial truth value with precising definitions. To the extent that the definition departs from clearly established common usage, it is similar to the stipulative definition. See id. at 144. 
which is consistent with lexical use, while also providing some stipulation clearly limiting the definitional parameters of the term. ${ }^{27}$

The problem with utilizing the precising definition to define terms such as "parent," "mother," and "father," however, is that these terms are not merely ambiguous terms; they are equivocal as well. ${ }^{28}$ The term "parent," for example, is used to denote both biological progenitors who do not raise the child ("natural parent") and persons who are not biologically related but who do care for the child ("adoptive parent"). Indeed, it is precisely in disputes between diverse parties such as these that legal conflicts arise. Therefore, a definition that will distinguish these conflicting claims to parental status is required. The precising definition falters because it does not serve to delineate the better of the inconsistent uses of a term that is used in everyday language.

In our attempt to arrive at a cogent definition for the term "parent," we confront a basic dilemma. On the one hand, if we attempt to remain faithful to the everyday use of the term, we are prevented from arriving at a set of necessary and sufficient conditions for its use because the term commonly is used to describe both the noncustodial biological progenitor and the nonbiologically related custodian of the child. On the other hand, if we depart from these everyday uses of the term, we run the risk of abandoning an important part of its meaning. To the extent that the rights of "parents" and the tradition of parenthood are contingent upon this meaning, abandoning the lexical meaning abjures the very basis for these rights and traditions. Ultimately, the problem with finding a purely formal definition of "parent" is that the formal definition ignores the social, moral, and legal contingencies which have shaped our shared social intuitions about parenthood. Thus, the delineation of an appropriate definition must account for the contingent factors which have shaped this social meaning. In essence, the search for a unifying conception of parenthood cannot be simply an exercise in semantics; instead, it must be a genuinely normative quest that accounts for a great deal of empirical evidence and moral assessment.

27 For example, the term "person" might be defined as a human being after the point of viability. The term reflects common usage but also sets a definite line which delimits the scope of the definition, thereby recognizing that the previable fetus is not a "person" under the definition.

28 Ambiguity may be distinguished from equivocation as follows. Ambiguity, on the one hand, refers to vague definitional boundaries. At what width does a chair become a sofa? At what stage of development does a fetus become a person? When does facial hair become a beard? These various issues, ranging from the mundane to the profound, are all examples of conceptual ambiguity. Equivocation, on the other hand, is where one term is used in two different and perhaps conflicting ways. Thus, the term "guilty" is used to denote both individuals who have committed a crime, whether or not they are convicted-this is "factual guilt"and those who are convicted of a crime, even if they did not in fact commit the crime-"legal guilt." See I. Copi, supra note 24, at 113 (discussing ambiguity and equivocation). 


\section{The Parental-Rights Doctrine}

Creating a legal definition of "parent" is problematic because it is virtually impossible to delineate a list of necessary and sufficient conditions with which to define "parent." Given that the problem of parenthood cannot be resolved by definitional fiat, perhaps we would do better to look for a provisional definition that focuses on what we expect parents to do, that is, by examining the legal rights which parents possess and the extent to which these rights are limited by other doctrines. Immediately, however, one faces a new complexity-the fundamental dichotomy underlying our present system of family law between the rights of the parent in the child and the interests of the child. This dichotomy has been played out in modern legal practice as a conflict between the parental-rights doctrine and the best-interests-of-the-child test. ${ }^{29}$

The parental-rights doctrine holds that the fit parent has a right to the custody, care, and companionship of his or her child even if the interests of the child would be better served by being placed with a third party. ${ }^{30}$ The best-interests test, by contrast, does not focus on the claims of the competing potential custodians but instead attempts to define the interests of the child in being placed with one or another party. ${ }^{31}$ The conflict between these two custody approaches is most poignant when the best interests of the child clearly require the child's removal from the parent or, even more dramatically, the irrevocable termination of parental rights.

Traditionally, the parental-rights doctrine took nearly absolute priority. In early English history, parental rights were remarkably similar to property rights; indeed, as late as the tenth century, parents held life

29 See Russell, Within the Best Interests of the Child: The Factor of Parental Status in Custody Disputes Arising from Surrogacy Contracts, 27 J. Fam. L. 587, 620-27 (1988-1989) (discussing tension between these two doctrines); see also McGough \& Shindell, Coming of Age: The Best Interest of the Child Standard in Parent-Third Party Custody Disputes, 27 Emory L.J. 209, 212-14, 230-44 (1978) (examining changing balance between these two doctrines in parent/third-party custody disputes).

30 In deciding custody between parents, courts consider the child's best interests, but they generally do not when deciding custody between a fit parent and a third party. Professor Russell states:

Courts have long held that primary custody should be granted to the parent who would best serve the interests of the child, and that when the parent's and child's interests conflict, the child's interests must prevail. Courts and scholars also agree, however, that these principles should not operate to remove a child from a fit parent merely to enhance the child's life chances.

Russell, supra note 29 , at 600 .

31 See Mnookin, Child-Custody Adjudication: Judicial Functions in the Face of Indeterminacy, 39 Law \& Contemp. Probs. 226, 257-61 (1975) (discussing difficulty of determining child's best interests); see also Ruddick, Parents and Life Prospects, in Having Children: Philosophical and Legal Reflections on Parenthood 124-37 (O. O'Neill \& W. Ruddick eds. 1979) (providing philosophical account of nature of parenthood and child's interests). 
and death sway over their children, at least while the children were young. ${ }^{32}$ Recently, however, the priority of the parental-rights doctrine has been placed in question. ${ }^{33}$ In particular, considerations of parental unfitness ${ }^{34}$ and the child's best interests have acted as limits on parental rights. ${ }^{35}$ Indeed, many states have statutes which provide for awards of custody to nonparents if it is in the best interests of the child. ${ }^{36}$

Still, even the more limited, modern parental-rights approach reflects our basic intuition that the parents of the child should not be deprived of their right to nurture their child. ${ }^{37}$ For example, all states apply a presumption that placement of the child with its natural parent is in the best interests of the child. ${ }^{38}$ While custody awards to nonparents occasionally are made over the claims of fit parents, ${ }^{39}$ the fit parent re-

32 See McGough \& Shindell, supra note 29, at 210.

33 See Mnookin, supra note 31, at 246-49 (arguing that, in some contexts, best-interests test appears to have taken precedence over parental rights); Page, Parental Rights, $1 \mathrm{~J}$. Applied Phil. 187, 188 (1984) (arguing that notion of parental right denigrated by holding that parents possess rights in their children only as long as they do not conflict with other social interests).

34 See McGough \& Shindell, supra note 29, at 226-28 (explaining parental-unfitness doctrine).

35 See Page, supra note 33, at 188.

36 See Mnookin, supra note 31, at 237.

37 See id. Mnookin poses the following hypothetical.

Suppose there are two couples, the Smiths and the Joneses. The Smiths wish to adopt a child. The Joneses have a four-day-old baby daughter whom they wish to keep ....

Suppose both Smith parents were well educated, wealthy, and healthy; loved children; and appeared to be highly successful parents with two older children. Suppose the Joneses were older; had no experience at child rearing; had severe financial problems; and Mr. Jones was in bad health. There are certainly plausible and perhaps even persuasive reasons to believe the child's "life chances" would be greater if placed with the Smiths. And yet, a decision to remove the daughter from the Joneses for placement with the Smiths would be considered by most in our society to be monstrously unjust.

Id.

38 See Russell, supra note 29, at 622 ; see also notes $245-46$ and accompanying text infra (discussing this presumption).

39 See, e.g., Painter v. Bannister, 258 Iowa 1390, 1400, 140 N.W.2d 152, 158 (custody of minor granted to maternal grandparents over father's objection so as not to disrupt child's development), cert. denied, 385 U.S. 949 (1966). Cases where a grant of custody is made to a nonparent usually involve situations where the child has been living with the nonparent and has established a psychological relationship. See Note, Psychological Parents vs. Biological Parents: The Courts' Response to New Directions in Child Custody Dispute Resolution, $17 \mathrm{~J}$. Fam. L. 545, 550 (1979). This is plainly distinguishable from a case where a child is removed from the custody of a fit parent to be placed with a nonparent. Such a decision would likely be unconstitutional. See notes 44-51 and accompanying text infra (discussing constitutional status of parents); cf. In re May, 14 Wash. App. 765, 769, 545 P.2d 25, 27 (1976) (refusing to place child under state guardianship, stating that mother had right to attempt parenting before removal proceedings could be instituted). But see In re East, 32 Ohio Misc. 65, 69, 288 N.E.2d $343,346-47$ (1972) (newborn infant removed from custody of its mother on theory of dependency, without showing of parental neglect). 
tains a number of rights independent of custody.$^{40} \mathrm{~A}$ nonparent may be awarded full parental status despite the competing claim of a natural parent where the natural parent of an illegitimate child has failed to establish rights in the child. ${ }^{41}$ This placement often occurs where the natural father has failed to establish a relationship with the child, either because of indifference or as a result of not knowing about the existence of the child, ${ }^{42}$ and where his parental rights already have been extinguished prior to the award of parental rights to a third party. ${ }^{43}$

The parental-rights doctrine, a creature of common law and more recently statutory law, is reinforced by its constitutional analogue. The Supreme Court has stated that parental rights are " "[r]ights far more precious . . . than property rights." "44 More specifically, "freedom of personal choice in matters of . . . family life is one of the liberties protected by the Due Process Clause of the Fourteenth Amendment." "45 The zone of family privacy and parental authority has been afforded both substantive and procedural protection under the due process clause. ${ }^{46}$ This cluster of constitutional protections includes the right of the family to live together ${ }^{47}$ the right of parents to raise their children as they deem fit, ${ }^{48}$ and the right of parents to educate their children without state interference. ${ }^{49}$ The procedural protections recognized pursuant to the due process clause require that parental rights may not be terminated without notice and a hearing, ${ }^{50}$ and without at least clear and convincing evidence of parental unfitness. ${ }^{51}$

40 See Note, The Legal Relationship of a Nonbiological Father to His Child: A Matter of Equity, 66 U. Det. L. Rev. 97, 98 (1988) (examining limits on grants of paternal status to nonbiologically related fathers).

41 See Quilloin v. Walcott, 434 U.S. 246, 256 (1978), in which a woman's new husband was allowed to adopt her child where the child's biological father had forfeited his parental rights by not marrying the mother or seeking to establish a relationship with the child. Essentially, the Court relied upon the best-interests test to permit the adoption where there was, in effect, no father in existence. See id. at 251.

42 See, e.g., M.H.B. v. H.T.B., 100 N.J. 567, 579, 498 A.2d 775, 781 (1985) (per curiam) (biological father of child, unaware of child's existence, lacked parental rights).

43 See notes 90-155 and accompanying text infra (discussing parental rights of unwed father).

44 Stanley v. Illinois, 405 U.S. 645, 651 (1972) (quoting May v. Anderson, 345 U.S. 528, 533 (1953)).

45 Smith v. Org. of Foster Families, 431 U.S. 816, 842 (1977) (quoting Cleveland Bd. of Educ. v. LaFleur, 414 U.S. $632,639-40$ (1974)).

46 See id.

47 See Moore v. City of E. Cleveland, 431 U.S. 494, 505-06 (1977).

48 See Wisconsin v. Yoder, 406 U.S. 205, 214 (1972).

49 See Pierce v. Soc'y of Sisters, 268 U.S. 510, 534-35 (1925); Meyer v. Nebraska, 262 U.S. 390,400 (1923).

so See Stanley v. Illinois, 405 U.S. 645, 655-57 (1972).

51 See Santosky v. Kramer, 455 U.S. 745, 758-68 (1982) (preponderance-of-evidence standard insufficient to deny parental rights). 
Parents, in short, retain a significant bundle of rights with respect to their children. These legal rights, while not defining "parent," help identify what is at stake in this debate over parenthood. Nevertheless, before resolving this controversy more vexing questions need to be examined. Who is eligible to be a parent? Does the law currently recognize any necessary or sufficient conditions for ascribing parental status?

II

\section{The Existing Law of Parenthood}

A consideration of the indicia of parental status should commence with an analysis of the legal issues surrounding procreation. This requires an examination of two fundamental issues. First, what is the right of procreation and to which activities does the right extend? More specifically, does the right of procreation encompass collaborative-reproduction technologies? Second, to whom does the right of procreation apply? These issues are considered in the two sections which follow.

\section{A. The Right of Procreation}

In Skinner v. Oklahoma, ${ }^{52}$ the Supreme Court held unconstitutional an Oklahoma statute providing for the involuntary sterilization of certain classes of offenders whose crimes were characterized by "moral turpitude." 53 While the case was decided on equal protection grounds, ${ }^{54}$ it since has been incorporated unofficially into substantive due process analysis as part of the privacy right elaborated years later in Griswold $v$. Connecticut ${ }^{55}$ and its progeny. ${ }^{56}$ However, despite these subsequent de-

52316 U.S. 535 (1942).

53 Id. at 537.

54 See id. at 541.

55 381 U.S. 479, 485-86 (1965) (law forbidding use of contraceptives intrudes upon right to marital privacy).

56 See, e.g., Roe v. Wade, 410 U.S. 113 (1973); Eisenstadt v. Baird, 405 U.S. 438 (1972). The Supreme Court has not ruled on the right of procreation since Skinner. Thus, the Court has never stated that the procreative right is an aspect of the privacy right. Nonetheless, the right to procreation does have all the indicia of a privacy right. First, analogous pre-Griswold privacy rights have been subsumed into modern substantive due process analysis. Thus, early cases such as Meyer v. Nebraska, 262 U.S. 390 (1923), which invalidated a law prohibitting instruction in any language other than English, and Pierce v. Soc'y of Sisters, 268 U.S. 510 (1925), which held unconstitutional a law forbidding education outside of public schools, have been recognized as part of the right to privacy. See, e.g., Roe, 410 U.S. at 159 (relying upon Griswold, Meyer, Pierce, and Skinner in privacy-right analysis).

Second, the right of procreation, at least superficially, involves similar issues as those encountered in other privacy-right cases. The rights to use contraception, to have an abortion, and to live with one's family-are all aspects of the privacy right as it has developed over the past quarter-century. See Allen, supra note 16, at 1786-91 (analyzing right of procreation as traditional privacy right); Note, A Taxonomy of Privacy: Repose, Sanctuary, and Intimate Decision, 64 Calif. L. Rev. 1447, 1466-78 (1976) (privacy right of intimate decisions includes 
velopments in the area of privacy rights, Skinner remains the only Supreme Court decision explicitly addressing the right of procreation.

Skinner is ambiguous for a number of reasons. First, the right of procreation elaborated in Skinner appears as a negative right to make procreational decisions without government interference. This is quite distinct from a positive right requiring government assistance to enforce reproductive-services contracts between commissioning couples and surrogates. ${ }^{57}$ Second, it is not clear whether the right of procreation extends beyond the scope of traditional two-party sexual reproduction. Specifically, although some state courts have taken a position on these matters, ${ }^{58}$ the Supreme Court has not determined whether the right extends to the use of artificial insemination by donor, in vitro fertilization, or surrogate-parenting arrangements. 59

Two further ambiguities in Skinner's procreative-rights analysis more directly related to the present discussion likewise remain unresolved. First, the substantive content of the right is unclear: does it protect only the biological act of reproduction, or also the corresponding right to parent the child? Second, even if the right applies in the context of collaborative reproduction, and particularly in surrogate-parenting arrangements, to whom does it apply? Does the right attach only to the biological progenitors-the sperm donor, whether or not he is also the intended father, and the surrogate in genetic surrogacy-or does it also extend to the couple possessing the prebirth intention to raise the child? The answer to each of these questions generally will depend on whether procreation is cast purely in biological terms or, alternatively, whether it encompasses an intentional dimension.

The first of these two issues concerns the extension of the right of procreation beyond biological reproduction to include the right to raise the child born through the procreative act. At least one scholar has argued that the right of procreation is not simply a right to beget and bear

rights of procreation, cohabitation, child-rearing, bodily integrity, in-home possession, and private sexual activities between consenting adults). But see Robertson, Procreative Liberty and the Control of Conception, Pregnancy, and Childbirth, 69 Va. L. Rev. 405, 414-20 (1983) (distinguishing freedom to procreate from freedom to control every related activity).

57 See In re Baby M, 109 N.J. 396, 447-49, 537 A.2d 1227, 1253-54 (1988) (rejecting claim of intended parent that his right of procreation required government enforcement of surrogate contract).

58 See, e.g., Doe v. Kelley, 106 Mich. App. 169, 173-74, 307 N.W.2d 438, 441 (1981) (right of procreation does not extend to surrogate arrangements); Baby $M, 109$ N.J. at 448,537 A.2d at 1253 (" $[\mathrm{t}] \mathrm{he}$ right to procreate very simply is the right to have natural children, whether through sexual intercourse or artificial insemination").

59 If the right of procreation is deemed to extend to collaborative reproduction, yet is treated as a negative right, the effect would be to limit greatly any government involvement in procreational choices-either to enforce or to criminalize collaborative-reproductive agreements. 
a child but includes the right to be a parent. ${ }^{60}$ This conclusion comports with the commonsense intuition that the procreative right is virtually empty unless it ensures progenitors the right to acquire parental rights in the child. While the contrary interpretation, which construes that right as nothing more than the right to pass along one's genes without a corresponding right to have custody of or to make decisions affecting the child, seems untenable, a range of intermediate positions entitling procreators to parental rights in certain situations has received support in various courts. ${ }^{61}$

The recent case of In re Baby $M^{62}$ will help formulate an intermediate approach to the right of procreation. The Baby $M$ case is one of the few decisions in which a court faced directly the task of elaborating the substantive content of the right of procreation. In Baby $M$, the Sterns commissioned Mary Beth Whitehead to act as a surrogate for them. ${ }^{63}$ Ms. Whitehead was artificially inseminated with the sperm of Mr. Stern and gave birth to a baby girl. ${ }^{64} \mathrm{Ms}$. Whitehead then changed her mind and attempted to retain custody of the child. ${ }^{65}$ Construing the scope of the right of procreation, the New Jersey Supreme Court stated:

The right to procreate very simply is the right to have natural children, whether through sexual intercourse or artificial insemination. It is no more than that. Mr. Stern has not been deprived of that right. Through artificial insemination of Mrs. Whitehead, Baby $M$ is his child. The custody, care, companionship, and nurturing that follow birth are not parts of the right to procreation ....66

Thus, according to the court, the right to procreation protects only the right to reproduce physically and possibly some limited aspects of parental rights. The court's ruling makes clear that the right of procreation does not include the right to raise and nurture the child. If it did, then conflicting claims to the custody of a child, as in divorce or contested surrogate arrangements, could not be resolved. ${ }^{67}$ The right, nonetheless, does render its possessor a legally recognized "parent."68

60 See O'Neill, Begetting, Bearing, and Rearing, in Having Children: Philosophical and Legal Reflections on Parenthood 25-26 (O. O'Neill \& W. Ruddick eds. 1979) (intent to procreate creates right, as well as duty, to raise child).

61 See Baby $M, 109$ N.J. at 466, 537 A.2d at 1263 (demonstrating intermediate position by granting visitation rights to Mrs. Whitehead, egg donor/gestational host).

62109 N.J. 396, 537 A.2d 1227 (1988).

63 Id. at $411,537 \mathrm{~A} .2 \mathrm{~d}$ at 1235.

64 Id. at $412,414,537$ A.2d at $1235-36$.

65 Id. at $415-16,537$ A.2d at 1237.

66 Id. at 448,537 A.2d at 1253 .

67 This is clear because while Mrs. Whitehead ultimately did not receive custody of the child, she was accorded visitation privileges as a parental right. See id. at 466,537 A.2d at 1263.

68 The decision to award custody of Baby $M$ to the intended parents, the Sterns, was based 
More specifically, the right of procreation elaborated in Baby $M$ is analogous to that possessed by noncustodial parents: it includes the minimum rights to take part in certain fundamental child-rearing decisions, to visit the child, ${ }^{69}$ to bring an action modifying the custody award, ${ }^{70}$ and the duty to provide child support. ${ }^{71}$ In short, exercising the right of procreation is sufficient to make one a "parent" in the legal sense. Of course, where no conflicting claims exist by parties who have exercised the right, the right to raise the child will inure to both parents. Thus, the pivotal question now becomes: does the right of procreation extend to biological progenitors or intended parents, and for what reason? ${ }^{72}$ The analysis prompted by this question can be distilled into two questions under current legal doctrine. First, is genetic consanguinity a sufficient condition for recognizing the biological progenitor as a parent? Second, is it a necessary condition of parenthood?

\section{B. To Whom Does the Right of Procreation Attach?}

The right of procreation attaches to those parties identified by the courts as the mother and father of the child at birth. ${ }^{73}$ This section examines common-law doctrines, recent statutory law, and constitutional law to determine which participants courts currently designate as parents. This section considers to what extent current concepts of mother-

on the additional determination of the child's best interests, not an absolute right to custody on the part of the Sterns. Thus, Mr. Stern's genetic contribution to the arrangement rendered him a "parent" under the court's analysis. The ultimate decision regarding custody, however, was determined under the best-interests test. See id. at 448-54, 537 A.2d at 1254-57.

69 See J. Areen, Family Law 462-506 (2d ed. 1985) (discussing visitation rights).

70 See id. at 536-51 (discussing modification of custody awards).

71 See id. at 591-675 (discussing child support).

72 See Allen, supra note 16, at 1760-68, 1771-81, 1786-92 (analyzing parental rights in light of privacy rights and procreative rights of intended parents and surrogate); Jackson, Baby $M$ and the Question of Parenthood, 76 Geo. L.J. 1811, 1813-16 (1988) (examining definition of parent and role of intent in determining parental status); Robertson, supra note 56, at 427-36 (discussing right of procreation in context of collaborative reproduction). One commentator has put forth one of the most cogent analyses of the right of procreation and the stages of conception, pregnancy, and childbirth, proposing a scheme for reconciling the rights and interests of diverse parties in reproductive arrangements. She argues for an intentional analysis of the right of procreation limited by the privacy-right concerns of the surrogate. As such, her article is one of the few to draw a conceptual distinction between the right of privacy and the right of procreation. See Note, Redefining Mother: A Legal Matrix for New Reproductive Technologies, 96 Yale L.J. 187, 192-202 (1986).

73 For example, in the Baby $M$ case, the right of procreation attached to $M r$. Stern and Mrs. Whitehead, the two parties that would be considered the mother and father of Baby M under traditional legal rules. Because Ms. Stern would not be considered the mother of the child under traditional law, the right of procreation did not extend to her. See In re Baby M, 109 N.J. 396, 447-48, 537 A.2d 1227, 1253 (1988) (concluding that egg donor/gestational host was "natural mother . . . entitled to retain her rights as a mother," then discussing Mr. Stern's right of procreation without any indication that Mrs. Stern also could possess this right). 
hood and fatherhood are biological constructs and questions whether biology should act as either a necessary or sufficient condition to parenthood.

\section{Who is Mother: The Presumption of Biology and the Role of Gestation}

The "presumption of biology" manifests the once monolithic and still pervasive legal principle that the mother of the child is the woman who bears the child. ${ }^{74}$ This principle reflects the ancient dictum mater est quam gestation demonstrat (by gestation the mother is demonstrated). ${ }^{75}$ This phrase, by its use of the word "demonstrated," has always reflected an ambiguity in the meaning of the presumption. It is arguable that, while gestation may demonstrate maternal status, it is not the sine qua non of motherhood. Rather, it is possible that the common law viewed genetic consanguinity as the basis for maternal rights. ${ }^{76}$ Under this latter interpretation, gestation simply would be irrefutable evidence of the more fundamental genetic relationship.

The debate and, indeed, the distinction itself were in the past only a matter of academic interest, but today, with the increased use of reproductive technologies, it is a matter of palpable significance. For example, in the context of gestational surrogacy, ${ }^{77}$ different women play the genetic and gestational roles. The egg donor, who is not capable of bringing the fetus to term, provides a number of fertilized ova to the surrogate with the intention that, upon the birth of the child, the egg donor will assume parental obligations for the child. However, if the surrogate changes her mind and wishes to retain custody of the child, how should the law respond?

Application of the presumption of biology as it traditionally has been understood would give legal priority as mother to the surrogate. But it is not clear that this application comports with either the deeper meaning of the presumption of biology or modern sensibilities regarding this conflict. Indeed, the term "biology" itself is susceptible to equivocal use, implicating both the genetic and the gestational aspects of procreation.

Commentators who have considered this problem have come to op-

74 See Note, supra note 72, at 190-92 (discussing ineffectiveness of presumption of biology in resolving surrogate-mother issues).

75 See OTA, Infertility, supra note 1, at 282.

76 See Johnson v. Calvert, No. X 633190 (Cal. App. Dep’t Super. Ct. Oct. 22, 1990) (holding that egg donor/intended mother had parental rights over surrogate and discussing common-law background) (on file at New York University Law Review).

77 This is a surrogate arrangement accompanied by the use of in vitro fertilization, where the surrogate gestator is not the same woman as the egg donor. See id. at 3. 
posite conclusions. A number of scholars argue that the egg donor should take precedence because the hereditary and biological characteristics of the child are derived from her. ${ }^{78}$ Others, however, argue that the surrogate's greater physical and emotional involvement in carrying the fetus, along with the advantage of simplicity in identifying the gestational host, gives the surrogate a greater right to be designated the legal mother of the child. ${ }^{79}$ The relative merits of these alternatives are evaluated in Part III of this Article. ${ }^{80}$ The analysis in the remainder of this subsection focuses on the legal rights that flow from the gestational role.

The courts have confronted explicitly the conflict between the egg donor/intended mother and gestational host only twice. ${ }^{81}$ In each case, a decision was rendered favoring the egg donor/intended mother. In the first case, Smith v. Jones, 82 the proceeding was a "set-up" to allow the egg donor to adopt the child, and, in accordance with the surrogate agreement, the surrogate did not contest the ruling. ${ }^{83}$

In the second and more recent case, Johnson v. Calvert, 84 the parties actively disputed the same issue. In Calvert, the surrogate, Anna Johnson, had agreed to act as gestational host for the Calverts, the intended parents and sperm and egg donors. ${ }^{85}$ However, near the end of her pregnancy, Ms. Johnson changed her mind and decided that she wanted to retain custody of the child. ${ }^{86}$ In a loosely reasoned oral opinion, the court awarded full parental rights to the Calverts, analogizing the role of Ms. Johnson to that of a foster parent. ${ }^{87}$ Thus, the Calvert court implicitly recognized that in a dispute between the egg donor/intended mother and the gestational host, the former has the superior legal claim. Aside from these two cases, the presumption of biology provides for an irrebut-

78 See, e.g., Brahams, The Hasty British Ban on Surrogacy, 17 Hastings Center Rep. 16, 18-19 (1987); Samuels, Warnock Committee: Human Fertilisation and Embryology, 51 Medico-Legal J. 174, 176 (1983).

79 See, e.g., Annas, Redefining Parenthood and Protecting the Embryos: Why We Need New Laws, 14 Hasting Center Rep. 50, 50-51 (1984) (presumption favoring surrogate mother provides certainty of identification at time of birth); Note, Rumpelstiltskin Revisited: The Inalienable Rights of Surrogate Mothers, 99 Harv. L. Rev. 1936, 1950-51 (1986) (social and emotional bonds formed in childbirth process favor surrogate mother's rights).

80 See notes 190-307 and accompanying text infra.

81 While the two cases represent the only existing law on this issue, numerous legislative proposals have been made to remedy the uncertain state of the law in this respect. See OTA, Infertility, supra note 1, at 284 (discussing some legislative proposals).

82 No. 85.532014 DZ (Mich. Cir. Ct. Mar. 14, 1986) (on file at New York University Law Review).

83 Id. at 2.

84 No. X 633190 (Cal. App. Dep’t Super. Ct. Oct. 22, 1990) (on file at New York University Law Review).

85 Id. at 3.

86 Id. at 11.

87 See id. at 5-6. 
table presumption of motherhood in favor of the birth mother in all states except Arkansas and perhaps Nevada. In these states, the irrebuttable presumption appears to have been abrogated in the case of surrogate arrangements.88 Additionally, the status of the birth mother is protected in a variety of other ways including the prohibition in every state against enforcing prebirth agreements to consent to adoption. ${ }^{89}$

While both Smith and Calvert were decided in favor of the egg donors/intended mothers, in other contexts the birth mother appears to retain various rights. Thus, the legal significance of the gestational role is uncertain. As for the genetic role, its relevance is best developed in the context of a discussion of paternal rights.

\section{Who is Father: The Presumption of Legitimacy and the Significance of the Genetic Relationship}

We now turn to a consideration of two related issues. First, what are the legal requisites for ascription of parental rights? Second, what rights does a natural parent possess by virtue of the genetic relationship between parent and child? It is significant that these two questions are elaborated separately, because, as it turns out, there is only a loose legal relationship between legally recognized fatherhood and genetic consanguinity. The second question is posed and distinguished from the first so that some general conclusions can be drawn regarding the legal significance of the genetic relationship for the egg donor, as well as the sperm donor.

In general, fatherhood is a status which is predominantly a function of the family relationship. More specifically, it is a status accorded to men who entertain certain kinds of relationships with the mother and the child. Ultimately, there is only a contingent relationship between this relational status and the genetic connection between putative father and child. 90

At common law, the "presumption of legitimacy" provided that any child born to a woman while she was married would be considered the

88 The Arkansas statute provides in relevant part:

(b) A child born by means of artificial insemination ... shall be presumed to be the child of the woman giving birth ... except in the case of a surrogate mother, in which event the child shall be that of: 1) The biological father and the woman intended to be the mother if the biological father is married; or 2) The biological father only if unmarried; or 3) The woman intended to be the mother in cases of a surrogate mother when an anonymous donor's sperm was used for artificial insemination.

Ark. Stat. Ann. § 9-10-201 (1991); see also Nevada Rev. Stat. Ann. § 127.287(5) (Michie \& Supp. 1989) (lawful surrogacy contract exception to bar against using money to secure adoption).

89 See OTA, Infertility, supra note 1, at 281, table 14-2 (containing chart of applicable adoption laws).

90 See notes 96-105 and accompanying text infra. 
child of her husband.91 Indeed, the husband did not have to be physically present at the time of conception. In the words of one court: "If a husband, not physically incapable, was within the four seas of England during the period of gestation, the court would not listen to evidence casting doubt on his paternity."92

Correlatively, at common law, a third party possessed no right to bring an action to establish his paternity; rather, this right is a relatively recent creation of statutory law. ${ }^{93}$ The common-law presumption would bar a man who wanted to acknowledge responsibility for a child born to a married woman even if one or both of the spouses testified that the child was that of the third party. ${ }^{94}$ Despite its harsh ring to the modern ear, this irrebuttable presumption of legitimacy, enshrined as Lord Mansfield's Rule, 95 was well-motivated. The rule not only protected the integrity of the family but also served to ensure the legitimation of the child in a period when illegitimacy carried with it a terrible social stigma and resulted in severe legal consequences. ${ }^{96}$

Under modern statutory law, paternity still is largely presumed. Indeed, in a number of states the presumption of legitimacy remains irrebuttable. ${ }^{97}$ Thus, despite the invention of scientific methods conclusively establishing nonpaternity ${ }^{98}$ and positively establishing paternity to within a small fraction of certainty, 99 third parties still are precluded from bringing actions to establish paternity. In the majority of

91 See M. Field, Surrogate Motherhood 118-21 (1988).

92 In re Findlay, 253 N.Y. 1, 7, 170 N.E. 471, 472 (1930).

93 See A v. X, 641 P.2d 1222, 1222 (Wyo.) (under Wyo. Stat. \$ 14-2-104 (1977), child, her mother, or man presumed to be her father may bring paternity action to determine whether there is father-child relationship), cert. denied, 459 U.S. 1021 (1982).

94 See, e.g., State ex rel. H. v. P., 90 A.D.2d 434, 437, 457 N.Y.S.2d 488, 490-91 (1982) (upholding husband's paternal rights where separated wife claimed to have withdrawn from artificial insemination program and instead conceived baby with unnamed third party).

95 See Goodright v. Moss, 2 Cowp. 591, 98 Eng. Rep. 1257 (1777).

96 See Sass, The Defense of Multiple Access (Exceptio Plurium Concubentium) in Paternity Suits: A Comparative Analysis, 51 Tul. L. Rev. 468, 498-99 (1977) (discussing historical legal status of illegitimate child). During the early period of the common law, illegitimate children had no rights against their male progenitors: the "bastard" could neither inherit nor claim support and was even deprived of legitimation by the subsequent marriage of its natural parents. See id. at 499. Thus, these children were called filii nullius ("children of no one"). Id. at 498. In the sixteenth century, however, the Poor Laws partially ameliorated this situation. See Poor Law Act, 18 Eliz. lc. 3 (1576). Under the Poor Laws, illegitimate children were accorded the right to seek support, although they still were not permitted to inherit. See Sass, supra, at 499.

97 See M. Field, supra note 91 , at 118 n.12 (by Oklahoma statute, wife denied opportunity to establish husband's nonpaternity); id. at 119 n.19 (California and Oregon law apply conclusive presumption that cohabiting husband is father of child).

98 See The Chi. Daily L. Bull., July 21, 1989, at A5.

99 See id. (predicting that paternity trials eventually will become unnecessary). 
those states in which the presumption of legitimacy is rebuttable, ${ }^{100}$ the presumption can be challenged only by the mother of the child or her husband. ${ }^{101}$ Thus, third parties attempting to establish paternity require the cooperation of one of the spouses. Only in a minority of states can a third party challenge the presumption on his own. ${ }^{102}$

Under the Uniform Parentage Act (UPA or Act), ${ }^{103}$ a third party may bring an action to establish paternity only when there is no presumed father under another section of the Act. ${ }^{104}$ Thus, the husband of the mother of the child retains legal rights simply by virtue of his relationship with the mother. ${ }^{105}$ The legal nexus between a nonbiologically related father and child also is recognized by permitting consensual artificial insemination by donor. ${ }^{106}$ This rule protects the paternal status of

100 See, e.g., Cal. Evid. Code $\S 621$ (b)(West Supp. 1991).

101 See, e.g., Cal. Evid. Code $\$ 621$ (c)-(d) (West Supp. 1991).

102 See M. Field, supra note 91 , at 118-21 (discussing issues involved in third-party challenges).

103 Unif. Parentage Act §§ 1-29, 9A U.L.A. 579-622 (1973).

104 Id. $\S 6(c), 9 A$ U.L.A. at 594. Section 4 of the Act provides, in part:

(a) A man is presumed to be the natural father of a child if:

(1) he and the child's natural mother are or have been married to each other and the child is born during the marriage, or within $\mathbf{3 0 0}$ days after the marriage is terminated ...;

(2) before the child's birth, he and the child's natural mother have attempted to marry each other by a marriage solemnized in apparent compliance with law, although the attempted marriage is or could be declared invalid ...;

(3) after the child's birth, he and the child's natural mother have married, or attempted to marry, each other by a marriage solemnized in apparent compliance with law, although the attempted marriage is or could be declared invalid, and

(i) he has acknowledged his paternity of the child in writing filed with the [appropriate court or Vital Statistics Bureau].

(ii) with his consent, he is named as the child's father on the child's birth certificate, or

(iii) he is obligated to support the child under a written voluntary promise or by court order;

(4) while the child is under the age of majority, he receives the child into his home and openly holds out the child as his natural child; or

(5) he acknowledges his paternity of the child in a writing filed with the [appropriate court or Vital Statistics Bureau], which shall promptly inform the mother of the filing of the acknowledgment, and she does not dispute the acknowledgment within a reasonable time after being informed thereof, in a writing filed with the [appropriate court or Vital Statistics Bureau]. If another man is presumed under this section to be the child's father, acknowledgment may be effected only with the written consent of the presumed father or after the presumption has been rebutted.

Id. $\S 4,9$ A U.L.A. at $590-91$. Section 4 (b) provides that the presumptions are rebuttable by clear-and-convincing evidence. Id. § 4, 9 U.L.A. at 303-04.

105 See, e.g., County of San Diego v. Brown, 80 Cal. App. 3d 297, 303, 145 Cal. Rptr. 483, 486 (1978) (conclusive presumption that defendant was child's father barred defendant from adducing evidence that he did not father child).

106 Consensual AID requires that the husband's consent to artificial insemination be in writing. See OTA, Infertility, supra note 1, at 244. In addition, under the UPA, the procedure 
the surrogate's husband while simultaneously providing that the sperm donor is not to be considered the father of the child. ${ }^{107}$ It is worth underscoring that this presumption applies only in marital relationships and does not extend to either heterosexual or homosexual cohabitation. ${ }^{108}$

While recognition of the presumption of legitimacy, in its various manifestations, has been conducive to the development of artificial insemination, it poses a significant obstacle to surrogate arrangements. While the wife of an infertile husband, with the assistance of the sperm donor, may plan to conceive and raise the child born of the AID arrangement, the situation is different where an infertile wife and her fertile husband seek the assistance of a married surrogate. In the latter instance, the presumption of legitimacy prevents the sperm donor/intended father from a claim to paternity of the child. Thus, in at least eighteen states, the husband of the surrogate will be considered the child's father. ${ }^{109}$

Understanding the legal framework for determining paternal rights also requires an examination of the constitutional dimension. Within the last two decades, the Supreme Court increasingly has involved itself in the process of explicating the constitutional rights of the unmarried male in establishing paternity. Two general rules have emerged from this case law. First, where the mother of the child is unmarried, the biological connection does afford the biological father a "foot in the door," permit-

must be performed under the supervision of a licensed physician. See Unif. Parentage Act § 5(a), 9 U.L.A. 301.

A number of cases have arisen where women artifically inseminated themselves at home. See, e.g., Jhordan C. v. Mary K., 179 Cal. App. 3d 386, 394, 224 Cal. Rptr. 530, 535 (1986) (provisions of UPA held inapplicable where woman used friend's sperm to inseminate herself, thereby allowing friend to petition to establish paternity). Before the Uniform Parentage Act and relatively early in the period in which AID became popular, the status of AID was uncertain. In one case, an Illinois superior court found that consensual AID failed to legitimize the child and rendered the wife guilty of adultery. Doornbos v. Doornbos, 23 U.S.L.W. 2308 (1954), appeal dismissed, 12 III. App. 2d 473, 139 N.E.2d 844 (1956). The first case to recognize that the presumption of legitimacy extended to consensual AID was Strnad v. Strnad, 190 Misc. 786, 787, 78 N.Y.S.2d 390, 392 (1948).

For specific discussions of AID issues, see Andrews, The Stork Market: The Law of the New Reproductive Technologies, 70 A.B.A. J. 50, 53 (1984); Hollinger, From Coitus to Commerce: Legal and Social Consequences of Noncoital Reproduction, 18 U. Mich. J.L. Ref. 865 (1985); Robertson, supra note 56; Wadlington, Artificial Conception: The Challenge for Family Law, $69 \mathrm{Va}$. L. Rev. 564 (1983); Note, Reproductive Technology and the Procreative Rights of the Unmarried, 98 Harv. L. Rev. 669 (1985); Special Project, Legal Rights and Issues Surrounding Conception, Pregnancy and Birth, 39 Vand. L. Rev. 597 (1986).

107 See Unif. Parentage Act § 5, 9A U.L.A. 592-93.

108 See Jhordan C., $179 \mathrm{Cal}$. App. 3d at 395, $224 \mathrm{Cal}$. Rptr. at 535 (presumption of legitimacy does not accord parental status to man with whom biological mother lived).

109 See Andrews, supra note 106, at 53 (discussing history of presumption of legitimacy in AID cases); In re Baby Girl, 9 Fam. L. Rep. (BNA) 2348 (Ky. Cir. Ct. Jefferson City Apr. 5, 1983) (presumption of legitimacy operates to deny paternity even when both surrogate and sperm donor/intended father wished to have parental rights accorded to intended father and his wife). 
ting him to establish a relationship with the child and justifying certain procedural safeguards of that relationship. ${ }^{110}$ Failure to establish this relationship, however, will result in the eventual extinction of these rights. ${ }^{111}$ Second, the biological progenitor of a child does not enjoy a constitutional right to establish paternity or to seek any form of legal recognition of the relationship if the mother of the child is married to another man, even where he has actively sought to establish a relationship with the child. ${ }^{112}$

Stanley v. Illionis, ${ }^{113}$ the first of four Supreme Court cases to address the right of an unmarried father to establish or maintain a legally recognized relationship with his child, involved a challenge to the constitutionality of an Illinois statute that conclusively presumed every unwed father unfit to care for his children. ${ }^{114}$ Appellant Stanley had lived with his children and their mother for eighteen years without benefit of marriage. ${ }^{115}$ Upon the mother's death, the State declared the children its wards and assumed responsibility for their care and custody without affording Stanley a hearing or establishing his unfitness. ${ }^{116}$ The effect of the state rule was to deny Stanley status as the legally recognized parent of the children. ${ }^{117}$ The Supreme Court rejected this statutory scheme because it violated both procedural due process and equal protection guarantees. ${ }^{118}$ Implicit in the Court's decision was the view that Stanley was indeed a "parent" for constitutional purposes, notwithstanding the State's more restrictive legislative definition.119 According to the Court, therefore, under the Constitution, a state may not make marriage a sine qua non for ascription of paternal rights.

This first elaboration of the paternal rights of unmarried men conceivably could have been interpreted as a constitutional protection of the genetic relationship itself. By this theory, a man achieves constitutional

110 This is apparent as a synthesis of the following cases: Lehr v. Robertson, 463 U.S. 248 (1983); Caban v. Mohammed, 441 U.S. 130 (1979); Quilloin v. Walcott, 434 U.S. 246 (1978); Stanley v. Illinois, 405 U.S. 645 (1972). See notes $111-43$ and accompanying text infra.

111 See Lehr, 463 U.S. at 248 (1983); Quilloin, 434 U.S. at 246 (1978); notes 119-28, 135-41 and accompanying text infra.

112 See Michael H. v. Gerald D., 491 U.S. 110, 129-32 (1989); notes $144-149$ and accompanying text infra.

113405 U.S. 645 (1972).

114 See id. at 648.

115 Id. at 646.

116 Id.

117 The statutory definition of "parent" at issue in Stanley included "the father and mother of a legitimate child, or the survivor of them, or the natural mother of an illegitimate child." The definition did not include unwed fathers. Id. at 650 .

118 See id. at 657-58.

119 The Court held that the "state's interest in caring for Stanley's children is de minimis if Stanley is shown to be a fit father." Id. Thus, part of what it means to be a "parent" for constitutional purposes is a presumption of fitness. 
protection as parent of his child by virtue of the genetic relationship alone. ${ }^{120}$ As we shall see, however, this interpretation later was rejected as unduly broad.

The next step in the almost dialectical development of this uncertain area came six years later in Quilloin v. Walcott.121 Quilloin involved a Georgia statute permitting the adoption of a child born out of wedlock over the objection of the male progenitor if he had not taken steps to legitimize the child. ${ }^{122}$ Here, the mother had married when the child was three years of age and sought to have her husband adopt the child eight years later. ${ }^{123}$ The biological progenitor sought to block the adoption of the child upon the filing of the adoption petition, ${ }^{124}$ which occurred eleven years after the birth of the child. Even then, the petitioner-biological progenitor did not seek custody but only objected to the adoption of the child by its mother's husband with whom the child had lived for most of its life. ${ }^{125}$

A unanimous Supreme Court upheld the state court's finding that the adoption petition was granted properly over the petitoner's objection, rejecting petitioner's due process and equal protection claims. ${ }^{126}$ Significantly, the Court distinguished Stanley by invoking the best-interests-ofthe-child standard under which it determined that the adoption was appropriate, because it gave legal recognition to an already established family unit. ${ }^{127}$

As previously noted, however, the best-interests test cannot be the basis for terminating parental rights in the absence of a showing of unfitness. ${ }^{128}$ Indeed, the Quilloin Court noted this, stating that due process would be offended if the state were to attempt to force the breakup of a natural family in the name of the child's best interests. ${ }^{129}$ Therefore, the only plausible interpretation of Quilloin consistent with the parentalrights doctrine is that, for constitutional purposes, the petitioner was not a "parent" of the child. By failing to assume any significant responsibility in the eleven years since the child's birth, the petitioner had lost, or had never fully actualized, his status as the parent of the child. While the

120 See Lehr v. Robertson, 463 U.S. 248, 271 (1983) (White, J., dissenting) (father's interest entitled to constitutional protection because biological relationship exists, not because of that relationship's quality).

121434 U.S. 246 (1978).

122 See id. at $248-49$.

123 Id. at 247.

124 Id. at 250.

125 Id. at 247.

126 See id. at 254-56.

127 See id. at 255.

128 See note 30 and accompanying text supra.

129 See Quilloin, 434 U.S. at 255. 
Quilloin Court did not adopt this view explicitly, subsequent developments render this the most meaningful interpretation of the Court's reasoning. ${ }^{130}$

Caban v. Mohammed, ${ }^{131}$ decided one year later, involved the conflicting claims of two unmarried parents both of whom had maintained joint custody of their children until the mother left to marry another man. ${ }^{132}$ In Caban, the Court upheld the father's constitutional challenge, on equal protection grounds, to a New York statute permitting an unwed mother, but not an unwed father, to prevent adoption by withholding consent. ${ }^{133}$ While the New York statute was similar to the Georgia statute under attack in Quilloin, ${ }^{134}$ the Court struck down the New York statute as an overbroad gender-based classification. ${ }^{135}$ Operative in the Court's decision was its finding that the petitioner's relationship with his children was sufficiently "substantial" to warrant protection. ${ }^{136}$

In Lehr $v$. Robertson, ${ }^{137}$ the last of its four cases addressing a biological father's claims of parental rights to a child born out of wedlock, the Court elaborated upon the scope of the constitutional recognition of an unmarried man's parental rights. In Lehr, the Court explicitly rejected petitioner's claim that the due process and equal protection clauses of the fourteenth amendment, as interpreted by Stanley and Caban, gave an unwed father an absolute right to notice and an opportunity to be heard before the child could be adopted by the subsequent husband of the child's mother. ${ }^{138}$ Again, the Court's decision turned on the relationship of the genetic father to the child. Rejecting petitioner's due process claim, the majority stated that he had "never supported and rarely seen" the child in the two years between the child's birth and the petition for

130 See Lehr v. Robertson, 463 U.S. 248, 261-62 (1983) (suggesting that parental rights can be extinguished by failure to exercise them); cf. Caban v. Mohammed, 441 U.S. 380, 389 n.7, 393 n.14 (1979) (noting appellant's failure in Quilloin to act as father toward his child as important factor).

131441 U.S. 380 (1979).

132 Id. at 394.

133 See id. at 382, 394. Under the New York statute, to block an adoption, an unwed father was required to prove that the adoption would not be in the child's best interests. See id. at 386-87. In Quilloin, by contrast, the Georgia statute allowed an unwed father to legitimate a child and gain parental rights, including the right to block an adoption. See Quilloin, 434 U.S. at 249.

134 See Quilloin, 434 U.S. at 248.

135 See Caban, 441 U.S. at 388 n.7 (noting that Georgia statute in Quilloin was similar to New York statute in Caban).

136 See id. at 393-94 \& n.14; see also Note, Caban v. Mohammed: Extending the Rights of Unwed Fathers, 46 Brooklyn L. Rev. 95, 109-10, 115-16 (1979) (concluding that Caban's recognition of qualitative aspects of parental relationship will provide guidance for legislation).

137463 U.S. 248 (1983).

138 See id. at 250. 
adoption by the mother's subsequent husband. ${ }^{139}$ The Lehr Court also addressed the relevance of the biological relationship directly:

The significance of the biological connection is that it offers the natural father an opportunity that no other male possesses to develop a relationship with his off'spring. If he grasps that opportunity and accepts some measure of responsibility for the child's future, he may enjoy the blessings of the parent-child relationship and make uniquely valuable contributions to the child's development. If he fails to do so, the Federal Constitution will not automatically compel a State to listen to his opinion of where the child's best interests lie. ${ }^{140}$

Thus, according to the Lehr majority, the biological tie provides a foundation upon which the progenitor may build, if he wishes, a parent-child relationship and become a legal "father."141

The Lehr dissent, which took issue with the majority's characterization of the significance of the biological relationship, noted that a "mere biological relationship' is not as unimportant in determining the nature of liberty interests as the majority suggests."142 Indeed, the dissent appeared to argue that the biological relationship warrants protection of the father's rights regarding the child. ${ }^{143}$ The disparity in the respective views of the majority and dissent may be reduced to two varying conceptions of the basis of parental rights-one requiring a psychological component characterized by a measure of emotional and financial commitment to the child, the other strictly biological.

Taken together, Stanley, Quilloin, Caban, and Lehr require something more than a biological link between progenitor and child to award

139 Id. at 249. The Court noted:

As we have already explained, the existence or nonexistence of a substantial relationship between parent and child is a relevant criterion in evaluating ... the rights of the parent. . . . Because appellant, like the father in Quilloin, has never established a substantial relationship with his daughter, the New York statutes at issue in this case did not operate to deny appellant equal protection.

Id. at 266-67 (citations omitted). The dissent raised the same inquiry, but read the facts differently, alluding to a pattern of deliberate concealment of the child by the mother, accompanied by persistent attempts on the part of appellant to locate mother and child and to establish a relationship with the child. See id. at 269 (White, J., dissenting).

140 Id. at 262.

141 Of course, the progenitor, by himself, may not absolve himself of the duties of parenthood, such as the payment of child support. See J. Areen, supra note 69 , at $665-76$ (examining enforcement of child-support orders). Where, however, another is willing to assume these duties, the Court has appeared to embrace the possibility that the biological progenitor may irrevocably lose the right to parental status.

142 Lehr, 463 U.S. at 271 (White, J., dissenting) (citations omitted).

143 Justice White's dissent stated: "Whether Lehr's interest is entitled to constitutional protection does not entail a searching inquiry into the quality of the relationship but a simple determination of the fact that the relationship exists." Id. at 272 (White, J., dissenting) (emphasis in original). But see text accompanying note 137 supra (discussing further Lehr dissent). 
even noncustodial parental rights to an unwed man. Moreover, it is unlikely that the Lehr dissent stands for the bald pronouncement that genetic consanguinity alone is sufficient for ascribing parental rights. After all, Quilloin, decided just five years earlier, was a unanimous opinion. ${ }^{144}$ Further, it is unlikely that even the Lehr dissenters would hold unconstitutional a provision similar to article five of the Uniform Parentage Act, providing that a sperm donor is not to be treated as the legal father of a child conceived through artificial insemination. ${ }^{145}$ Thus, it is clear that neither statutory law nor the Federal Constitution protects a man's parental status based solely upon the genetic connection.

The rights of a biological father are even more restricted where the mother of the child is married to another man. In Michael H. v. Gerald $D .,^{146}$ the Supreme Court held that California's presumption of legitimacy did not violate the due process rights of the biological progenitor of a child by preventing him from establishing his status as the child's father. ${ }^{147}$ Although the putative father had established through blood tests a probability greater than 98 percent that he was the natural father of the child, ${ }^{148}$ the Court invoked the common-law tradition of placing the integrity of the family unit and the status of the child above the claims of the natural father. ${ }^{149}$ The Court reached its holding despite the progenitor's commitment to the child and his active assertion of paternity, ${ }^{150}$ in contrast to the appellants in Quilloin and Lehr.

Michael $H$. represents a potent endorsement of the common-law limitation of the natural father's paternal rights. More importantly, it clearly reiterates the theme that parental rights are not solely a function of one's status as a genetic progenitor. With this case, the Supreme Court rejected a strictly biological conception of parenthood in favor of broader considerations.

The significance of the decision must not be overstated. Neither Michael $H$. nor its predecessor decisions render the genetic relationship of the father to the child irrelevant. It is very unlikely, for example, that

144 See Quilloin v. Walcott, 434 U.S. 246, 247 (1978).

145 See Unif. Parentage Act $\S 5$, 9A U.L.A. 593. Thus, the unwed father's relationship with the mother of the child establishes rights that the sperm donor clearly lacks. Indeed, it might not even be necessary that a "father" have had sexual relations with the child's mother. See, e.g., Jhordan C. v. Mary K., 179 Cal. App. 3d 386, 224 Cal. Rptr. 530 (1986) (friend of mother permitted to establish paternal relationship with child born after mother inseminated herself with his sperm, partly because parties' conduct reserved his status as family member).

146491 U.S. 110 (1989).

147 See id. at $118-20$.

148 Id. at 114.

149 See id. at 124. The Court concluded by wryly stating that the biological father's claim "is not the stuff of which fundamental rights qualifying as liberty interests are made." Id. at 127.

150 See id. at 114-15. 
the Court would object to state laws that dilute the presumption of legitimacy-and therefore strengthen the claims of the genetic father-by permitting either spouse to rebut it $^{151}$ or to state laws that permit a challenge by the putative natural father. ${ }^{152}$ Finally, even where the presumption remains conclusive, in actuality most legal fathers are biological fathers. Thus, even if it is true by contingent coincidence that most fathers are genetically related to their children, the fact has achieved recognition and legitimacy in the law.

In sum, fatherhood is a function of the confluence of three factors: the man's biological relationship with the child, ${ }^{153}$ his legal or social relationship with the child's mother, ${ }^{154}$ and the extent of his social and psychological commitment to the child. ${ }^{15 s}$ While in reality the first factor rarely is isolated from the latter two, the purpose of this exercise has been

151 See text accompanying notes $97-102$ supra. However, even where permitted, the ability of the spouse to rebut the presumption of legitimacy has been limited in certain situations. For example, where a man has held himself out as the father of a child born during marriage, only to have his wife inform him, upon divorce, that the child is not his, the wife will be estopped from testifying that the child was not that of her former husband. See, e.g., Atkinson v. Atkinson, 160 Mich. App. 601, 609-12, 408 N.W.2d 516, 519-20 (1987) (relying upon doctrine of "equitable parent" to achieve result); M.H.B. v. H.T.B., 100 N.J. 567, 568, 498 A.2d 775, 775 (1985) (husband equitably estopped from denying paternity after child had come to rely on relationship); New York ex rel. H. v. P., 90 A.D.2d 434, 440-41, 457 N.Y.S.2d 488, $492-93$ (1982) (equitable estoppel precluded wife from requiring blood test to establish her husband's nonpaternity); cf. Berrisford v. Berrisford, 322 N.W.2d 742, 745 (Minn. 1982) (equitable estoppel not applied against husband where child was too young to rely upon relationship).

152 See M. Field, supra note 91 , at $120 \mathrm{n} .23$ (Illinois and Wisconsin statutes construed to let putative father try to establish rights).

153 Controversy has arisen regarding the due process rights of foster and adoptive parents. While the Supreme Court has not ruled on the constitutional status of adoptive parents, it did address the question as to whether foster parents have the same due process rights as natural parents. In Smith v. Org. of Foster Parents, 431 U.S. 816 (1977), the Court strongly suggested in dicta that foster parents lack due process rights equivalent to those possessed by natural parents. The Court stated, "[n]o one would seriously dispute that a deeply loving and interdependent relationship between an adult and a child in his or her care may exist even in the absence of blood relationship." Id. at 844 . Nevertheless, "the usual understanding of 'family' implies biological relationships, and most decisions treating the relation between parent and child have stressed this element." Id. at 843 . In the end, the Court appeared to create a distinction based on natural law, arguing that the relationship between foster parent and child is a creation of the state, whereas the biological relationship between parent and child is grounded in a "liberty interest in family privacy [which] has its source, and its contours ... not in state law, but in intrinsic human rights, as they have been understood in 'this Nation's history and tradition.' " Id. at 845 (quoting Moore v. City of E. Cleveland, 431 U.Ș. 494, 503 (1977)).

154 While marriage traditionally has been the most important type of relationship, ascription of paternal rights also may depend upon the type of nonmarital relationship. See, e.g., Jhordan C. v. Mary K., 179 Cal. App. 3d 386, 397-98, 224 Cal. Rptr. 530, 537-38 (1986) (despite statute precluding sperm donors from asserting paternity, friend of mother permitted to establish paternal relationship with child born after mother inseminated herself with his sperm, partly because relationship was between social acquaintances).

155 See notes 109-10 and accompanying text supra. 
to attempt to draw some general conclusions about the way in which the law currently treats this variable in isolation.

\section{In Re Baby M:156 The Biological Interpretation of the Right to Procreate.}

The arguments above demonstrate that a biological link is not, as a matter of the constitutional right to procreation, sufficient to create parental rights. Not all biological parents are procreators. However, the Baby $M$ court clearly suggested that a biological link is a necessary condition for procreators. Thus, it held that the right of procreation applied only to Mrs. Whitehead, the surrogate, and Mr. Stern, the sperm donor/ intended father, by virtue of their respective biological contributions to Baby M, and not to Mrs. Stern, the intended mother. ${ }^{157}$ This biological interpretation of the right to procreate inextricably links the right to reproduce with the biological capacity to do so.

This approach raises numerous questions. First, one may inquire whether a gestational host, who is not genetically related to the child, is also a procreator. The recent ruling in Johnson v. Calvert strongly suggests that this is not the case. ${ }^{158}$ Note that if gestation alone is deemed sufficient to give the host a stake in the child, ${ }^{159}$ then three conflicting claims founded upon the right of procreation are possible: the claims of the sperm donor, the egg donor, and the gestational host. Second, interpreting the right of procreation to apply solely to those having made a biological contribution to the child, as opposed to those who may have had some instrumental, though nonbiological, role in creating the child, arguably is both overinclusive and underinclusive in scope. It is overinclusive by allowing those with a relatively insignificant role in the procreative process to acquire a right in the child. ${ }^{160}$ For example, a sperm

156109 N.J. 396, 537 A.2d 1227 (1988).

157 See id. at 441-44, 537 A.2d at 1248-50 (contract was held ineffective for granting parental rights to Mrs. Stern, who had no biological connection to child).

158 See notes $84-89$ and accompanying text supra (discussing Calvert case). Gestational surrogacy is still relatively infrequent; the first reported instance in the United States took place in 1985. See OTA, Infertility, supra note 1, at 36 . The process typically involves the use of in vitro fertilization and embryo transfer to the womb of a woman other than the egg donor. See id. at 255 .

159 See Annas, supra note 79, at 50-51 (arguing that gestation alone should trump claims of other parties to procreative relationship).

160 The relative insignificance of the biological contribution as a basis for ascribing the right of procreation can be seen by comparing the facts of the Baby $M$ case with those of our opening scenario where the intended parents biologically were unrelated to the child. From the intended father's standpoint in each of the two scenarios, the only distinction is that, in the $B a b y M$ case, the intended father contributed his own sperm while the sperm of an anonymous third party was used in the opening scenario. But surely this factor alone should not be the basis for according full parental rights to the intended father and custodial privileges to the intended mother in the former case, while denying them in the latter. 
donor contributing his issue to third parties wishing to have a child would satisfy a necessary condition to acquire parental rights in the child even though he never may have intended to parent the child. ${ }^{161}$ Simultaneously, the biological interpretation of the right is underinclusive by precluding those who lack the biological capacity to reproduce from exercising the right in a constitutionally protected manner. This interpretation precludes even the intended parents in the procreative relationship from asserting their right to procreate and their corresponding interest in the child simply because they lack the biological ability to reproduce. ${ }^{162}$

As the law currently exists, the legitimate exercise of the right of procreation includes the right to parent a child. ${ }^{163}$ If the rationale in Baby $M$ is followed, however, only those who possess the biological capacity to reproduce are deemed to possess the right to procreation..$^{164}$ Thus, only those with the capacity to reproduce have a constitutional guarantee to do so. Ironically then, the right protects those who are least likely to need its protection.

\section{Questioning the Reliance on Biology: Privacy versus Procreation}

The right of procreation typically is construed as one aspect or dimension of the right of privacy. ${ }^{165}$ And yet, the rights of privacy and procreation are distinct both in their nature and in the types of activities each protects. As Professor Robertson has maintained:

[C]hoices about who may conceive, bear, or rear a child are distinct from choices about the conduct that occurs in the process of conceiving, bearing and rearing. In other words, the freedom to procreate is distinct from freedom in procreation. Freedom to control every activ-

161 See notes $100-09$ supra (discussing laws limiting right of sperm donors to claim paternity).

162 Significantly, this is not a situation where a party possesses a right in theory but lacks the capacity to exercise it, as with certain economic or social rights. The distinction is important. If the infertile party possessed a constitutional right to procreate, the state could not prohibit collaborative-reproductive arrangements absent a compelling state interest. Thus, infertile persons with the resources to pay others for their biological contributions to the procreative act, but forbidden to do so by statute, differ from indigent persons who cannot afford an education, for in the latter case, the barrier is economic, while in the former, the barrier is legal. It illustrates the difference between economic and legal barriers to note that, in Roe v. Wade, 410 U.S. 113 (1973), the Court held that women had a constitutional right to abortion in certain circumstances, but in Harris v. McRae, 448 U.S. 297 (1980), the Court held that there was no constitutional mandate for the state to provide abortion services when women could not afford them.

It may turn out that the positive/negative right distinction is philosophically unsound. If so, the distinction between possessing a right without the opportunity to exercise it and not possessing a right at all will fall.

163 See text accompanying notes 60-61 supra.

164 See text accompanying notes $156-57$ supra.

165 See notes 56-57 and accompanying text supra. 
ity related to procreation-to determine how conception will occur, to manage the pregnancy, to decide how, when, where, and with whom parturition occurs, or how the neonatal period will be managed-may be of great significance to individuals and may also deserve protection. Although these activities may be lumped under the broad rubric of procreative freedom, analytically they involve choices distinct from the decision to procreate, which is the decision to conceive, gestate, or rear another person. ${ }^{166}$

In short, the right of privacy, which encompasses the right to use contraceptives, ${ }^{167}$ the right to an abortion, ${ }^{168}$ and a variety of other activities associated with a right not to procreate, ${ }^{169}$ is distinct conceptually from the right to procreate. More specifically, the right of privacy is nonrelational while the right to procreate is relational in character. ${ }^{170}$ Thus, while the exercise of the right of privacy is not dependent upon the consent or cooperation of others-for example, a woman need not seek the consent of another, even her husband, to obtain an abortion during the first trimester of her pregnancy ${ }^{171}$ - the right of procreation does depend upon the acts of others in at least one respect and, arguably, in a second as well. First, because it takes two to procreate, the exercise of the right is dependent upon the cooperation of another. ${ }^{172}$ Second, the procreative right arguably is contingent upon the constructive consent of the resulting child. A parent must meet certain minimal conditions in order to acquire the right to be a parent. ${ }^{173}$ While actual consent by an unborn child is an obvious impossibility, the notion of constructive consent is an accurate metaphorical reflection of the general intuition that parents must meet a minimum condition of fitness. While failure to meet this condition cannot undo the physical act of procreation, the rights of the parent in the child may be terminated as a result of the parent's failure to meet this minimal condition of fitness. ${ }^{174}$

\footnotetext{
166 Robertson, supra note 56, at 410.

167 See Griswold v. Connecticut, 381 U.S. 479 (1965).

168 See Roe v. Wade, 410 U.S. 113 (1973).

169 See note 56 supra (discussing right of procreation as part of privacy right).

170 Relational rights can be exercised only with the assistance or, at a minimum, the consent of others. Nonrelational rights, by contrast, are individual rights the legitimate exercise of which is not contingent upon the consent or participation of others. See Floyd \& Pomerantz, Is There a Natural Right to Have Children?, in Morality and Moral Controversies 135-136 (J. Arthur ed. 1981).

171 See Planned Parenthood v. Danforth, 428 U.S. 52, 69 (1976).

172 Thus, the act of rape can never be a legitimate exercise of the procreative right. See text accompanying notes 186-88 infra (discussing relevance of rape).

173 See notes 34-36 and accompanying text supra (discussing parental unfitness).

174 The right to family integrity is a fundamental right protected by the fourteenth amendment. See Roe v. Conn, 417 F. Supp. 769, 779 (D. Ala. 1976). Thus, statutes permitting the removal of a child from the home or the termination of parental rights on grounds of neglect or parental unfitness are subject to the compelling state-interest test. Id. But where the state
} 
The rights of privacy and procreation also differ conceptually in the nature of their respective relations to other rights. The right of privacy is derivative of a generalized notion of personal autonomy or bodily integrity, ${ }^{175}$ whereas the right of procreation is fundamental, and does not flow from some other, more fundamental right. ${ }^{176}$ The right to procreate is the right to bring a child into the world in an effort to have a family. ${ }^{177}$ As such, it is more than a right of personal expression. ${ }^{178}$

The distinction being drawn here has important ramifications for determining who should be treated as the parent of a child. Even if the right of privacy is intimately associated with the biological concomitants of procreation, pregnancy, and childbirth, the right of procreation, as a distinct normative claim, need not be associated with the biological $\mathrm{ca}$ pacity to reproduce. The right of procreation instead can be viewed simply as a normative safeguard to protect the intention to create and raise a

can show parental unfitness by clear-and-convincing evidence, the termination of parental rights is constitutionally permissible. See Santosky v. Kramer, 455 U.S. 745, 747-48 (1982).

175 See Comment, A Taxonomy of Privacy: Repose, Sanctuary, and Intimate Association, 64 Calif. L. Rev. 1447, 1471-73 (1979) (discussing which matters related to bodily integrity receive constitutional protection); id. at 1482 (discussing various interpretations of right of privacy). It is not clear which of these two varying notions, personal autonomy or bodily integrity, more clearly approximates the right of privacy. In Roe v. Wade, 410 U.S. 113 (1973), the Court stated that the right to an abortion is not predicated upon a right to do with one's body as one wishes:

The privacy right involved, therefore, cannot be said to be absolute. In fact, it is not clear to us that the claim asserted by some amici that one has an unlimited right to do with one's body as one pleases bears a close relationship to the right of privacy previously articulated in the Court's decisions. The Court has refused to recognize an unlimited right of this kind in the past.

Id. at 154. The right of privacy also does not approximate a right of personal autonomy similar to John Stuart Mill's harm principle. Mill's principle states:

[T] he sole end for which mankind are warranted, individually or collectively in interfering with the liberty of action of any of their number, is self-protection. That the only purpose for which power can be rightfully exercised over any member of a civilized community, against his will, is to prevent harm to others. ... In the part which merely concerns himself, his independence is, of right, absolute. Over himself, over his own body and mind, the individual is sovereign.

J.S. Mill, On Liberty 16 (Promoetheus Books ed. 1986) (n.p. 1859). The right of personal autonomy, encompassing psychological and life-style choices, is broader than a right of bodily integrity, strictly speaking.

176 See O'Neill, supra note 60 , at 26 (discussing distinction between basic and derived rights).

177 In this respect, the view of the right of procreation put forth here diverges from Robertson. Under my view, the intention to parent the child is necessary for the legitimate exercise of the right of procreation. This intention is not necessary in Robertson's view. See Robertson, supra note 56, at 460-61. It appears that even the desire to pass one's genes along to a succeeding generation is sufficient for the right to be exercised under Robertson's interpretation. See id. at 408-10.

178 Compare C. Fried, Right and Wrong 151-52 (1978) (parental rights are an extension of personal rights) with Page, supra note 33, at 192 (rejecting this view). 
child. ${ }^{179}$ Biological capacity, on this view, is neither necessary nor sufficient for ascribing the right to procreate. Thus, while surrogate hosts, such as Mary Beth Whitehead in Baby $M$, are protected by constitutional privacy rights in a wide range of decisions regarding whether and how to continue the pregnancy, ${ }^{180}$ it is not correct to ascribe the right to procreate automatically to the gestational host or to the sperm or egg donors as the Baby $M$ court did in its recent decision. ${ }^{181}$

Adopting this intentional interpretation of the right of procreation would have fundamental significance for the issue of parental rights. Since the legitimate exercise of the right of procreation would accord parental status to the possessor of the right, those to whom the right of procreation does not apply would not have a cognizable claim to parent the child. Thus, where a conflict develops, as in the Baby $M$ case, between claims based upon intentionality and those predicated upon biology, the intentional parents ${ }^{182}$ would take legal priority as the parents of the child. In Baby $M$, if Mr. Stern possessed a right to procreate and an interest in the child at all, it should have been based not upon the slender thread of genetic consanguinity, but upon his actions initiating the procreative relationship. ${ }^{183}$ By this alternative analysis, Mrs. Stern, the intended mother, would have possessed the same right and interest.

The remainder of this Article is devoted to critiquing the current biology-centered view of the procreative right and defending an "intentionalist" account of the right of procreation outlined above. Before proceeding to these arguments, however, it will be helpful to consider two preliminary objections to an intentionalist justification for parental rights. First, one might be concerned that, if the intentional exercise of the right of procreation is the basis for parental rights, those who have not taken part in the creation of the child would be precluded from being

179 See notes 309-18 and accompanying text infra (discussing arguments predicated upon intentional aspect of parenting).

180 For example, the surrogate retains the right to an abortion. See Note, supra note 72, at $203 \mathrm{n} .61$ (discussing implications of this division of rights).

181 See In re Baby M, 109 N.J. 396, 448-49, 537 A.2d 1227, 1254 (1988). Thus, since a surrogate cannot constitutionally waive her right to an abortion, for example, this could not be the basis for a valid contractual provision. Whether the surrogate could be contractually liable for obtaining an abortion, however, is uncertain. See Simons, Rescinding a Waiver of a Constitutional Right, 68 Geo. L.J. 919, 919-24, 945 (1980) (examining propriety of allowing rescission of waiver of constitutional right). As a practical matter, it is likely that the intended parents would be entitled, at a minimum, to a return of any compensation paid to the surrogate. See Hill, In Defense of Surrogate Parenting Arrangements: An Ethical and Legal Analysis 284-94 (discussing legal issues surrounding surrogate's breach of contract) (dissertation available from UMI, 1990). Whether there also would be a cause of action for the intentional infliction of emotional distress, among other theories, for example, is unclear.

182 For the definition of intentional (or intended) parents, see note 12 supra.

183 See notes 309-18 and accompanying text infra (defending intentional view of parental rights). 
considered parents. For instance, would this approach exclude adoptive parents from the claim to parental rights? Clearly not. Exercising the right of procreation is sufficient as the basis for parental rights, but it is not necessary. There are other ways of becoming a parent in addition to procreating. Through death, adoption, or involuntary termination of parental rights, as in the case of a determination of unfitness, third parties may acquire parental rights after the fact. However, it is the procreators-the party or parties responsible for bringing the child into the world with the intention of raising it, the prime movers in the procreative relationship-who are the "parents" of the child at birth.

A second concern is that this reconstruction of the right of procreation will deny the biological progenitors of an unplanned, but ultimately wanted, child the opportunity to be considered the legal parents of that child. Once again, however, the objection is unwarranted. Intentionality acts as a trump for the intended parents when conflicting claims are made by parties who have contributed biologically to the creation of the child. Intentionality, however, is not the only way to acquire parental status. ${ }^{184}$ Where no party has intended to create a child, as in the case of the unplanned child, there are no intentional parents. Thus, the claims of the biological parents would take precedence.

To sum up the argument to this point, any coherent theory regarding the right of procreation must resolve first, what parental rights the right of procreation entails; second, whether biological consanguinity is either necessary or sufficient to claim the right of procreation; and third, which conditions limit the parental rights stemming from procreation. As to the first, it was suggested above that the right to procreation plausibly entails the parental rights to make decisions affecting the child and, other things being equal, custody rights. ${ }^{185}$ Further, once the right of procreation has been exercised, the person or persons exercising this right should be deemed the parents of the child at birth.

With regard to the second issue, biological consanguinity clearly should not be sufficient for application of the right of procreation. ${ }^{186}$ The

184 To protect the sanctity of the family, high standards should be established for proof of an intentional relationship. Thus, in the case of surrogate gestation, not only should the parties evince their understanding contractually, but also the contract should be reviewed by a court. This would require both the surrogate and the intentional parents to manifest publicly their intentions regarding the procreational relationship. Aside from the evidentiary benefits of judicial review, such a hearing would have the added psychological advantage of requiring the surrogate to come to terms with, and to declare publicly, her stated intention to relinquish the child. This hearing, which would take place prior to the process of artificial insemination, could be instrumental in weeding out prospective surrogates who are uncertain of their ultimate ability to carry out the agreement.

185 See text accompanying notes $60-72$ supra.

186 See text accompanying notes $179-83$ supra (critiquing $B a b y$ M's reliance on biology for ascribing parental rights). 
case of pregnancy by rape makes this clear. Though the assailant may be the genetic progenitor of the child, he cannot be deemed to have exercised his right to procreate in the course of the act of rape. Similarly, the Supreme Court's ruling in Michael $H .^{187}$ suggests that biological consanguinity does not itself guarantee its possessor the right to procreate. ${ }^{188}$ Thus, biological consanguinity is not sufficient for application of the right of procreation. But neither should biological consanguinity nor capacity be considered necessary for one to possess and exercise the right of procreation. The right of procreation should extend to anyone intending to have a child and capable of producing a child, either biologically or by putting together the necessary biological components with the assistance of others. As to the third issue mentioned above, while others subsequently may acquire parental rights in the child, as in the case of adoptive parents, this acquisition can happen only after the parental rights of the procreative agents have been terminated either voluntarily or in order to protect the child.

\section{III}

\section{The Claims of Biology Reconsidered}

We have a technology that takes Susan's egg and puts it in Mary's body. And so we ask, who is the mother? Who is the surrogate? Is Mary substituting for Susan's body, growing Susan's baby for Susan? Or is Susan's egg substituting for Mary's, growing into Mary's baby in Mary's body? Our answer depends on where we stand when we ask the question. 189

The "presumption of biology" and cases like Baby $M$ must be read as endorsing a view of parental rights that gives primacy to those who are related biologically or gestationally to the child. This Part considers and rejects a number of arguments which could be made for the priority of the genetic donors or the gestational host over the claims of the intentional parents.

\section{A. The Genetic Donor's Claims for Priority}

A number of commentators addressing the conflicting legal claims to parental status between an egg donor and a gestational host have come

187 Michael H. v. Gerald D., 491 U.S. 110, 129-32 (1989) (rejecting constitutional challenge to state laws extending presumption of legitimacy to child of marriage, holding third party with $98 \%$ chance of being child's father has no parental rights).

188 See id. at 121-23 (rejecting claim that natural father outside marriage has substantive liberty interest in obtaining parental recognition); notes $144-50$ and accompanying text supra.

189 B. Katz-Rothman, Recreating Motherhood: Ideology and Technology in a Patriarchal Society 44 (1989) (emphasis in original). 
down squarely on the side of the egg donor. ${ }^{190}$ While these commentators have adverted to a number of interrelated and overlapping considerations in their defense of the genetic bond, none has undertaken a systematic explication of these arguments. The following discussion sets forth what appear to be the two most compelling claims that can be made in defense of the genetic donor's priority. The first is predicated upon the unique biological relationship shared by parent and child. ${ }^{191}$ The second is a property-oriented argument based upon the person's right to any products of his or her body. ${ }^{192}$

\section{The Genetic-Identity Argument}

It is beyond dispute that an important aspect of parenthood is the experience of creating another in one's "own likeness." Part of what makes parenthood meaningful is the parent's ability to see the child grow and develop and see oneself in the process of this growth. Through this process, the parent views himself or herself as a creative agent in nature. This genetic identity accords the parent a kind of limited, genetic immortality, which one commentator has called "the sense of living on through and in one's sons and daughters and their sons and daughters."193

The significance of the genetic connection between parent and child undoubtedly is part of what makes infertility a painful experience. ${ }^{194}$ While adoption may satisfy one's desire to provide nurturance for a child, adoption cannot satisfy the yearning to create the child and to watch as a version of oneself unfolds and develops. It is, without doubt, this desire which impels some to use reproductive technologies and arrangements, including surrogate parenting, to create a child rather than to adopt. ${ }^{195}$ The fundamental nature of this generative role may have inspired one commentator to argue that, while gestational surrogacy poses no insurmountable moral problems, genetic surrogacy-where the surrogate conceives the child with the intention of giving it up to another-is morally condemnable. 196

The blood bond between parent and child has achieved both histori-

\footnotetext{
190 See, e.g., Brahams, supra note 78, at 18-19; Samuels, supra note 78, at 176.

191 See notes 193-205 and accompanying text infra.

192 See notes 206-17 and accompanying text infra.

193 R. Lifton, The Life of the Self 32 (1983) (emphasis in original).

194 The harmful symptoms of infertility include depression, avoidance of social occasions celebrating the birth or growth of children, the side effects of drugs used to combat the condition causing infertility, and marital tension. OTA, Infertility, supra note 1, at 37. Divorce is not an uncommon result of infertility where the fertile party wishes to remarry and start a family. Id.

195 See A. Overvold, Surrogate Parenting 81 (1988) (stating that genetic input is important motive in genetic parenting).

196 See Krimmel, The Case Against Surrogate Parenting, 13 Hastings Center Rep. 35, 35, 38 (1983).
} 
cal and mythological significance in every culture. ${ }^{197}$ This connection is a manifestation of both the act of creating the child and the ongoing similarity between parent and child. ${ }^{198}$ The significance of this latter feature is experienced both by parent and child, most noticeably when the natural parent and child meet for the first time. ${ }^{199}$ The importance of biological similarity is augmented by scientific developments over the past fifty years which strongly suggest that even variables such as psychological dispositions and personal proclivities in such intimate matters as spousal preference and occupational choice may be determined, at least in part, genetically. ${ }^{200}$ In sum, it is only natural that our sublime and complex feelings regarding this issue reflect precisely the sentiment that law should preserve as a family unit that which nature has rendered genetically similar.

While the foregoing manifests our general intuitions for the roles of genetic parents as they have developed historically in our culture, the historic basis for these rights is distinct from the type of situation under consideration in this Article. Here we are considering the genetic link unto itself, distinct from the cultural connotations attending the genetic relationship. Our hypothetical situation poses a sperm or ova donor who has no other involvement in the procreative relationship against a number of parties with competing claims. The genetic relationship itself should not be the basis for evaluating the parental claims of genetic donors above these other claims.

First, the sperm donor, who merely hands over a vial of sperm, typically is denied parental rights. ${ }^{201}$ The contribution of the egg donor, of course, requires a greater level of physical involvement and risk. ${ }^{202}$ While this factor may give that donor a claim intuitively stronger than

197 See N. Chodorow, The Reproduction of Mothering: Psychoanalysis of Gender (1978) (discussing masculine and feminine parental roles in different societies).

198 See J. Bluestein, Parents and Children: The Ethics of the Family 142 (1982) (stating that conception and birth are direct cause of emotional attachment to biological child).

199 For example, one adoptee, upon locating her biological mother, expressed delight simply at hearing a voice identical to hers emanating from the other end of the telephone line for the first time. A. Sorosky, A. Baran \& R. Pannor, The Adoption Triangle 159 (1984).

200 See E. Wilson, On Human Nature 15-51 (1978) (discussing claim that personal and, ultimately, social practices are predicated upon genetic foundation). I do not take a stand here on the ever-present nature-nurture debate. The point is simply that, just as physical traits are heritable, it is likely that the physical processes which underlie psychological functioning also are heritable. This is not rendered any less plausible by social conditions in the child-rearing environment which may reinforce certain psychological dispositions. Thus, a child with a psychological propensity toward learning may be reinforced in her pursuits by a mother with a similar disposition. See R. Lewontin, S. Rose \& L. Kamin, Not in Our Genes 83-130 (1984) (discussing influence of genes versus environment on intelligence).

201 See note 104 supra.

202 Ova are removed through a surgical process known as laparoscopy. See OTA, Infertility, supra note 1 , at 105-06. 
that of the sperm donor, that intuition rests on an argument regarding the greater psychological and physical involvement of the egg donor, rather than the genetic connection per se. The active role of parent as the creator of the child is lacking in the contribution of the genetic donors here. The sperm or egg donor plays the passive role of providing the seed from which the child will develop. This contribution, in itself, cannot be the basis for a claim to parental rights.

Second, it should not be relevant that the donor and child share similar physical or even psychological characteristics. As one commentator has pointed out, there is no difference genetically between the relationship of the donor and child and the relationship between full siblings. ${ }^{203}$ In either case, there is a fifty percent probability, with regard to any particular gene, that the pair will share that gene. ${ }^{204} \mathrm{By}$ itself, sharing fifty percent of a child's genetic make-up should give the biological progenitor no greater right to parent than it does a sibling. Indeed, if genetic similarity alone were sufficient for ascribing parental rights, an identical twin would possess a greater claim than the parent. ${ }^{205}$ The absurdity of this result demonstrates that genetic similarity alone should not serve as a basis for recognizing parental rights.

\section{The Property-Rights Argument}

The property-rights argument can be put into simple syllogistic form. The major premise states that persons possess property rights in the products, processes, and organs of their bodies and in any commodities developed from these sources. ${ }^{206}$ The minor premise provides that a child is a product of a person's genetic issue. Therefore, the syllogism concludes that the genetic progenitor should have property rights or quasi-property rights in the child.

There are, however, a number of preliminary difficulties with this argument. First, because a child is the genetic expression of two persons, a genetic progenitor would have only a half-interest in the child. Second, most sperm and eggs are sold to commercial sperm banks. ${ }^{207}$ Consequently, even under traditional principles of property law, the sperm and ova would belong to the purchaser who would have the right to dispose of them as he or she sees fit, within existing legal constraints, free and

203 See B. Katz-Rothman, supra note 189, at 37.

204 Id.

205 Identical twins carry all the same genes. Id.

206 This proposition must be qualified. Persons do not have an absolute right to dispose of their bodies as they deem fit. For instance, there are significant limitations on the sale of organs. See R. Scott, The Body as Property 179-97 (1981); Andrews, My Body, My Property, 16 Hastings Center Rep. 28, 28 (1986).

207 See Jansen, Sperm and Ova as Property, 11 J. Med. Ethics 123, 124 (1985) (examining ethical implications of unauthorized use of donated sperm, ova, and embryos). 
clear of any claims on the part of the gamete donor. ${ }^{208}$ Third, even if the sperm or ova had not been sold but had been appropriated accidentally as part of the reproductive process of another, the doctrine of accession might bar the claims of the genetic progenitors. Where a raw material has been remade so as to completely change its nature or greatly increase its value, accession requires that title in the object vests with the person who has performed the labor-in this case either the intending parents or, more literally, the gestational host. ${ }^{209}$ Thus, even if the propertyrights metaphor were appropriate in this situation, the sperm and ova donors would have no claim to the child.

Overlooking these objections, however, a more fundamental difficulty with the property-rights argument remains. While people may possess property rights in their genetic issue, they certainly do not possess property rights in the results of their genetic contributions. Put more simply, children are not property. While it is true that at common law parental rights were in many ways strikingly similar to property rights, ${ }^{210}$ this similarity no longer exists. ${ }^{211}$ Thus, while a sperm or egg donor may have something approximating a property right in his or her gametes, their status with respect to an embryo is less certain. ${ }^{212}$ The continuum running between the jurisprudential categories of property and personhood is unclear. For example, the progenitors of a frozen embryo awaiting implantation in the uterus may be treated as property owners in some contexts and as prospective parents in others. ${ }^{213}$ But

208 See R. Brown, The Law of Personal Property $\S 9.2$ (3d ed. 1955) (discussing passage of title in sale-of-goods context).

209 Before a court will apply the doctrine of accession, it must find that the raw material was used accidentally or in good faith. See 1 Am. Jur. 2d Accession and Confusion § 2 (1962). Also, the object must be substantially changed or increased in value. See Wetherbee v. Green, 22 Mich. 311 (1871) (rejecting plaintiff's replevin action for hoops made from wood cut from his land).

210 See McGough \& Shindell, supra note 29, at 209-17 (discussing development of state intervention in parent-child relationships). "As late as the tenth century in England, a parent ... could sell a child under seven into slavery." Id. at 209. Even as recently as the nineteenth century, a parent had a legal right over the child's property, services, and earnings. See id. at 210.

211 Parental rights now may be terminated, for example, when a parent is deemed unfit. See notes 33-36 and accompanying text supra.

212 The Warnock Report in Britain recommended that legislation be passed providing that embryos should not be treated like property. See Jansen, supra note 207, at 125 .

213 For example, while the progenitors of a frozen embryo together share the right to dispose of the embryo as they deem fit, this right may be lost to both parties in the event of divorce or passage of time. See Davis v. Davis, No. 180 (Tenn. App. Sept. 13, 1990) (LEXIS, States library, Tenn. file) (divorcing couple litigated disposition of frozen embryos which had not been implanted prior to divorce), leave to appeal granted sub nom. Stowe v. Davis, No. 180 (Tenn. App. Dec. 3, 1990) (LEXIS, States Library, Tenn. file); see also Andrews, The Legal Status of the Embryo, 32 Loy. L. Rev. 357, 402-03 (1989) (analysis of legal issues surrounding frozen embryos). 
certainly, upon birth, the property metaphor is no longer apposite.

Perhaps the property-rights argument could be amended to meet this objection by acknowledging that the parents do not retain property rights in the child but rather that their property rights in their gametes "mature" into parental rights with the growth of the fetus. However, the moral intuition underlying the doctrine of accession ${ }^{214}$ undermines the modified version of the property-rights argument. The link between gamete and newborn child is too attenuated to support a claim to parent the child by virtue of the genetic contribution alone. Where the genetic donor solely relinquishes his or her issue for the purpose of another carrying the child to term, with the understanding that the genetic donor will raise the child, the genetic donor has a compelling argument. In the absence of this intention, however, the claim is much weaker; and where there exists a clear intention that another will raise the child, the claims of the genetic progenitors are negligible.

This is not to say that the gamete donor has no interest in the use to which the sperm or ovum is put. For example, it has been suggested, perhaps crassly, that the right of the gamete producer is similar to the right of the manufacturer of a computer chip, or the distributor of some copyrighted material.215 While a party may sell the right to use, view, or listen to the material, the right to duplicate or alter it is not included. ${ }^{216}$ Analogously, the genetic progenitor would possess an interest in restricting the uses of his or her genetic material. The progenitor, for example, might have an interest in preventing the purchaser from using his or her gametes to create a race of genetically engineered automatons or to develop some interspecies hybrid. ${ }^{217}$

That the producers of sperm and ova have a interest in preventing certain uses of their issue, however, does not establish that they should be accorded parental rights. Where the gamete producer has transferred to another the right to use his or her issue for legally permissible forms of collaborative reproduction, he or she has relinquished any rights or interest in the issue as long as it is used as provided for by agreement. The genetic source may retain an interest in seeing that the bodily product is not used improperly, just as the publisher may prevent copyright infringement, but this interest gives the genetic source no right to parent the child, just as a publisher has no right to reclaim a book purchased for a legitimate purpose by another.

Thus, the argument for the priority of the genetic progenitor as parent of the child is not, in itself, compelling. To the extent that the genetic

\footnotetext{
214 See text accompanying note 209 supra.

215 See Jansen, supra note 207, at 124.

216 See id.

217 See id.
} 
progenitor does have a colorable claim to parent the child, it must be by virtue of some other form of contribution to the procreational arrangement.

\section{B. The Gestational Host's Claims for Priority}

God gave her the child, and gave her, too, an instinctive knowledge of its nature and requirements ... which no other mortal being can possess. And, moreover, is there not a quality of awful sacredness in the relation between this mother and this child. ${ }^{218}$

The claims for the moral and legal priority of the gestational host are much more compelling than are those of the genetic progenitors. At least five distinct genres of argument can be brought to bear in favor of the primary parental status of the gestational host. These include claims predicated on the prenatal and postnatal bonding between the birth mother and child; the best interests of the child; the harmful psychological effects to the birth mother resulting from compelled relinquishment of the child; the physical involvement of the birth mother in bringing the child into the world; and the extrinsic social and moral considerations which portend harmful consequences predicted to result from permitting the legal separation of birth mother and child. Each of these claims will be considered in turn.

\section{The Maternal-Bonding Argument}

The claim that a deep attachment or bond develops in the course of the prenatal and postnatal relationship between mother and child is, perhaps, the most popular and most controversial argument favoring the priority of the gestational host. ${ }^{219}$ The controversy is due, in part, to the

218 N. Hawthorne, The Scarlet Letter 113 (H. Levin ed. 1960) (n.p. 1850).

219 The bonding claim lies at the very heart of the attack on the proposed enforcement of surrogate contracts. See Suh, supra note 9, at 362 (bonding is among strongest human ties, profoundly affecting birth mother).

The claim is also the subject of numerous articles. See Belsky \& Rovine, Nonmaternal Care in the First Year of Life and the Security of Infant-Parent Attachment, 59 Child Dev. 157 (1988) (child's behavioral responses to others influenced by level of care rendered by primary caretaker); Chess \& Thomas, Infant Bonding: Mystique and Reality, $52 \mathrm{Am}$. J. Orthopsychiatry 213 (1982) (critiquing evidence supporting uniqueness of mother-infant attachment and idea that there is critical period for bonding); Egeland \& Farber, Infant-Mother Attachment: Factors Related to Its Development and Changes Over Time, 55 Child Dev. 753 (1984) (studying effect of socioeconomic factors on infant-mother bond); Fein, Men's Entrance to Parenthood, $25 \mathrm{Fam}$. Coordinator 341 (1976) (discussing parental duties as factor in reducing anxiety in paternal role); Fletcher \& Evans, Maternal Bonding in Early Fetal Ultrasound Examinations, 308 New Eng. J. Med. 392 (1983) (discussing how sensory contact with fetus facilitates bonding); Goldberg, Parent-Infant Bonding: Another Look, 54 Child Dev. 1355 (1983) (critical look at whether bonding hypothesis has been proven); Herbert, Sluckin \& Sluckin, Mother-To-Infant Bonding, 23 J. Child Psychology \& Psychiatry 205 (1982) (arguing that evidence fails to support critical-bonding-period hypothesis, especially in light of socioeco- 
fundamental implications that the bonding hypothesis has for our view of human nature and for our conception of the nature of the parent-child relationship. ${ }^{220}$

Accordingly, the bonding hypothesis is susceptible to a variety of interpretations and has taken on a corresponding number of diverse theoretical manifestations. First, an ancient claim, now recast in the parlance of sociobiology, asserts that there is a maternal instinct which biologically predisposes a woman to want to bear and nurture a child.221 A second view suggests that pregnancy and childbirth precipitate a battery of powerful psychoanalytic forces that facilitate the maternal bond. ${ }^{222}$ Third, several competing psychosocial theories view the maternal-child relationship as the result of a matrix of social influences. ${ }^{223}$ And, of

nomic factors and successful adoptions); Isabella, Belsky \& von Eye, Origins of Infant Mother Attachment: An Examination of Interactional Synchrony During the Infant's First Year, 25 Dev. Psychology 12 (1989) (arguing that mother-infant interaction is self-reinforcing: behavior of one influences and reinforces responses of other); Kennell \& Klaus, Mother-Infant Bonding: Weighing the Evidence, 4 Dev. Rev. 275 (1984) (arguing for critical-bonding-period hypothesis); Lamb, Early Mother-Neonate Contact and the Mother-Child Relationship, 24 Child Psychology and Psychiatry 487 (1983) (arguing that critical-bonding-period hypothesis is not supported by evidence); Lamb \& Hwang, Maternal Attachment and Mother-Neonate Bonding: A Critical Review, 2 Advances in Dev. Psychology 1 (1982) (same); Leifer, Psychological Changes Accompanying Pregnancy and Motherhood, 95 Genetic Psychology Monographs 55 (1977) (discussing change in maternal self-inage during first pregnancy and early postpartum period); Lewis \& Feiring, Infant-Mother and Mother-Infant Interaction Behavior and Subsequent Attachment, 60 Child Dev. 831 (1989) (examining synchronic aspect of mother-infant interaction); Myers, Mother-Infant Bonding: The Status of the Critical Period Hypothesis, 4 Dev. Rev. 240 (1984) (arguing that, on balance, early sensitivity period for maternal bonding has not been proven) [hereinafter Myers, Status]; Myers, Mother-Infant Bonding: Rejoinder to Kennell and Klaus, 4 Dev. Rev. 283 (1984) (same) [hereinafter Myers, Rejoinder]; Shtarkshall, Motherhood as a Dominant Feature in the Self-Image of Female Adolescents of Low Socioeconomic Status, 22 Adolescence 565 (1987) (arguing that plans for becoming parent and feelings about maternity are affected by socioeconomic status); van Ijzerdoorn \& van VlietVisser, The Relationship Between Quality of Attachment in Infancy and IQ in Kindergarten, 149 J. Genetic Psychology 23 (1988) (positive correlation found between quality of infant-tomother attachment and child's IQ).

220 Where the bonding hypothesis is viewed as a claim that parental feelings are the product of biologically preprogrammed factors, the implication is that social factors are less important than usually thought. Therefore, parenting, and the feelings of nurturance that accompany it, cannot be learned. See Shtarkshall, supra note 219, at 568-69 (discussing social and economic factors affecting feelings of adolescent girls concerning their self-image as potential mothers).

221 Kennell and Klaus come close to this position but are not unqualified biological reductionists because they admit that the bonding process may be affected by psychosocial factors. See Kennell \& Klaus, supra note 219 , at 276-77 (reviewing evidence of biologically produced sensitivity period and arguing for critical-bonding-period hypothesis); see also E. Wilson, supra note 200, at 15-53 (theoretical account of sociobiology and claim that biological mechanisms underlie social behavior).

222 See, e.g., S. Freud, Some Psychological Consequences of the Anatomical Distinction Between the Sexes, in 5 Collected Papers 195 (J. Strachey ed. 1959) (discussing penis envy, its renunciation, and female desire to nurture child).

223 Many commentators, particularly feminists, have attacked the biological conception in favor of a psychosocial or social learning view of motherhood. See, e.g., N. Chodorow, supra 
course, there are variations and combinations of these diverse themes which further frustrate any attempt to arrive at a univocal conception of the bonding phenomenon. ${ }^{224}$ Thus, the meaning of the term "bond" varies from one theoretical orientation to another. This lack of uniformity has important implications for the claim that bonding is an inevitable concomitant of pregnancy and childbirth. ${ }^{225}$

In addition to these theoretical difficulties, confusion exists as to whether bonding occurs before birth, after birth, or throughout both pregnancy and the neonatal period.226 The answer to this question appears to depend upon the researcher's theoretical orientation-biological determinists place much greater emphasis on prenatal factors than do those from a social-learning perspective. The question is confused further by conflating the mother-to-infant bond and the infant-to-mother bond. 227

note 197, at 40 (study of psychodynamic considerations advances sociological understanding of women's assumption of maternal role); G. Corea, The Mother Machine 283-99 (1985) (examining significance of social factors in development of gender identity and assumption of maternal role).

224 For example, bonding has been viewed as a fundamentally biological phenomenon which may be affected by social factors. See Kennell \& Klaus, supra note 219, at 276-77 (bonding affected by cultural and socioeconomic background as well as hospital-care practices); R. Lewontin, S. Rose \& L. Kamin, supra note 200, at 289 (human development is result of complex array of factors).

225 Biological theories generally suggest that the bond is immutable and inevitable provided there is contact during the critical period. Similarly, psychoanalytic theories appear to render behavior a function of unconscious motivational processes over which the woman has no conscious control. See, e.g., S. Freud, supra note 222, at 191-92. Social-learning theories, by contrast, suggest that behavior can be changed by altering psychological and social conditions which bring about certain behavior. See, e.g., N. Chodorow, supra note 197, at 205-06. For example, the maternal-infant bond may be simply the product of social influences which condition a woman to behave in certain ways toward her baby. If so, where social expectations toward the gestational host do not compare with those directed toward the biological mother who has intended to keep her child, the surrogate may not bond with the child. In short, the social-learning theories interpret human behavior as flexible and more amenable to social infuences. See Myers, Rejoinder, supra note 219. Thus, according to social-learning theory, the implications of the bonding hypothesis are less dramatic, at least where the social influences which affect the birth mother's relationship with the child can be altered. Id.

226 From the standpoint of mother-infant bonding, there are proponents of both the prenatal bond and the postnatal bond. Compare Fletcher \& Evans, supra note 219, at 392 (discussing development of prenatal mother-infant attachment) with Kennel \& Klaus, supra note 219, at 277-78 (discussing presence of postnatal mother-infant sensitivity period).

227 Four distinct types of bonds may be distinguished logically: a prenatal infant-to-mother bond, a prenatal mother-to-infant bond, a postnatal infant-to-mother bond, and a postnatal mother-to-infant bond. It is difficult to see how the first of these could be tested. For a discussion of the prenatal mother-to-infant bond, see Fletcher \& Evans, supra note 219, at 392-93 (bonding facilitated by ultrasound and sensory contact). For a consideration of the postnatal infant-to-mother bond, see Belsky \& Rovine, supra note 219, at 164-65 (child's behavior influenced by level of care); Egeland \& Farber, supra note 219, at 769 (socioeconomic factors affect child's attachment to parent). The postnatal mother-to-infant bond is the focus of the present discussion. 
Our knowledge of the emotional impact of pregnancy strongly suggests that there are as many feelings and experiences accompanying pregnancy as there are pregnant women. For some women, pregnancy is a time of significant emotional upheaval, psychological disequilibrium, and profound uncertainty in self-identity as their role changes from wife to mother and, possibly, from working woman to child caretaker. ${ }^{228}$ Others experience pregnancy, birth, and childcare with an unparalleled sense of personal wholeness.229 For still other women, the early phase of parenthood is a time of crisis exceeding even that of pregnancy. ${ }^{230}$

Still, despite these variations, the prenatal version of the bonding hypothesis is supported by a great deal of evidence, both scientific and anecdotal. Thus, women often report feelings of loyalty toward the fetus early in pregnancy, sometimes as early as the end of the first trimester. ${ }^{231}$ Quickening, the point at which a woman begins to feel the movements of the fetus, is important to the development of maternal feelings of attachment to the fetus. ${ }^{232}$ Reactions to quickening appear to be an example of the general correlation between the woman's increasing sensory awareness of the fetus and her feelings of loyalty and attachment to it.233 While both parents interact greatly with the fetus-touching, rubbing, and talking to it, often in response to fetal movements-women have a greater sense of the fetus as a separate individual, often attributing emotional responses to fetal movements. ${ }^{234}$ Finally, there is empirical support for the claim that women mourn after the loss of a baby, even a nonviable fetus. ${ }^{235}$

228 See Leifer, supra note 219, at 57-60 (1977) (analyzing empirical evidence on pregnant women's psychological mutations). These changes are particularly significant with the birth of a woman's first child. See A. Oakley, Women Confined 179-80 (1980).

229 See Leifer, supra note 219, at 89-90; see also K. Rabuzzi, Motherself 48-59, 109-20 (1988) (discussing changes in roles and self-perception brought about by pregnancy and childcare).

230 See Leifer, supra note 219 , at 89.

231 See Fletcher \& Evans, supra note 219, at 392.

232 See Leifer, supra note 219 , at 76. Quickening takes place some time around the end of the first or the begining of the second trimester, from 12 to 16 weeks of gestation. See Hellegers, Fetal Development, in Contemporary Issues in Bioethics 125, 127 (T. Beauchamp \& L. Walters eds. 1989).

233 Thus, it is suggested that ultrasonography, by which ultrasonsic pictures of the fetal form are taken, may facilitate feelings of attachment for the fetus on the part of both parents. See Fletcher \& Evans, supra note 219, at 392-93.

234 See Stainton, The Fetus: A Growing Member of the Family, 34 Fam. Rel. 321, 322-24 (1985) (studying prospective parents' impressions of appearance, communication, gender, temperament, and sleep-wake cycle of their fetus).

235 See Kennell, Slayter \& Klaus, The Mourning Response of Parents to the Death of a Newborn Baby, 283 New Eng. J. Med. 344 (1970) (reporting feelings of attachment before tactile contact between fetus and mother).

There appears to be a high correlation between attachment to the baby and anxiety directed toward the fetus. See Leifer, supra note 219 , at 91 . Further, high self-concern is corre- 
Yet the implications for parental-rights arguments are unclear. First, much hinges on the nature-nurture variations of the bonding hypothesis. Notwithstanding this evidence, there is widespread disagreement concerning the bonding hypothesis-or even whether bonding exists as a discrete phenomenon. ${ }^{236}$ As a preliminary matter, there are profound conceptual difficulties in the concept of bonding. ${ }^{237}$ It is not clear whether the bonding hypothesis, as conceived by its proponents, must necessarily entail some kind of biological link which transcends social factors and influences. For example, if bonding is simply the result of complex social factors which condition or motivate a woman to feel and behave in certain ways toward the child, then these factors can be mitigated by changing the social contingencies which shape the expectations of the gestational host. Indeed, numerous studies strongly suggest that socioeconomic circumstances affect a woman's emotional predisposition to the child. ${ }^{238}$ Even the most ardent proponents of the biological interpretation of the bonding hypothesis have qualified their earlier positions to admit that socioeconomic factors affect the mother-infant relationship. ${ }^{239}$ Other research refutes the claim that the prenatal bond is a universal concomitant of pregnancy. In one study, researchers asked ninety-seven new mothers when they first felt love for their babies. Only $41 \%$ first felt love during pregnancy. ${ }^{240}$ This response suggests that prenatal attachment is not an immutable biological imperative that supports a universal legal commitment to the priority of the gestational host.

Nonetheless, even if the prenatal-bonding hypothesis cannot support a general presumption in favor of the gestational parent, in many cases the gestational host does develop strong feelings toward the fetus before birth, and there is some indication that depriving her of the child will result in serious psychological consequences. ${ }^{241}$ These cases warrant serious moral consideration. Legal rights are not created in a vacuum.

lated with a low level of attachment to the fetus. See id. Also, there appears to be a correlation between maternal feelings early in pregnancy and the disposition toward the fetus much later in pregnancy. See id. at 91-92. Thus, a woman's attitude toward pregnancy early on may affect her subsequent level of attachment.

236 See note 219 supra.

237 See Herbert, Sluckin \& Sluckin, supra note 219, at 206 (analyzing difficulties in bonding hypothesis).

238 See, e.g., Egeland \& Farber, supra note 219, at 769; Herbert, Sluckin \& Sluckin, supra note 219, at 218-19; Myers, Status, supra note 219, at 256, 268; see also Shtarkshall, supra note 219 , at 568 (women of low socioeconomic backgrounds tend to have greater desire to become mothers).

239 See Kennell \& Klaus, supra note 219 , at 276.

240 Id. at 281 . Twenty-four percent first felt love for their children at birth, $27 \%$ felt love during the first week after birth, and the remaining $8 \%$ first felt love at some point after the first week. Id.

241 See notes $270-87$ and accompanying text infra (discussing psychological effects of relinquishment). 
Rights must account for tangible human feelings and relationships, particularly in an area such as this, where these feelings and relationships are most vulnerable. The weight that these considerations deserve, however, will depend upon the extent to which these feelings may be vitiated or prevented by changing the social expectations of the surrogate. Correspondingly less weight should be given to these considerations where the surrogate's attachment to the child can be precluded by her knowledge that she will not be recognized as the mother of the child.

As for the notion of a postnatal-bonding process or critical period in which the new mother is particularly susceptible to deep feelings of attachment as she interacts with the child, recent research has cast serious doubt on this hypothesis. Minimally, it is clear that there is no magical point at which the bonding process occurs. ${ }^{242}$ Moreover, numerous researchers have stated bluntly that there is no evidence to support the critical-period hypothesis. ${ }^{243}$

Arguments predicated upon the bonding hypothesis simply raise more questions than answers regarding the moral status of the gestational host. In addition to the theoretical problems mentioned thus far, it remains to be proven that the bonding process is qualitatively distinct from feelings of attachment for the child developed by others in the procreative process. The birth mother obviously is involved most directly with the physical development of the fetus and is the only one physically to experience tactile contact with the fetus. Nevertheless, there is little evidence for the claim that there is a qualitative difference between the feelings of the birth mother and those of another party to the procreative relationship. If there is no qualitative difference, then the claims of the gestational host predicated upon the prenatal-bonding hypothesis may be reduced to the contention that the birth mother has a superior claim to parent the child by virtue of her greater involvement with, and feelings of attachment for, the child at birth. While this may be an important argument in her favor, it does not carry the absolute moral weight conveyed by the onerous connotations of the term "bonding."

As for the argument predicated upon the postnatal-bonding hypothesis, two responses serve to answer the claims for the superiority of the

242 See Chess \& Thomas, supra note 219, at 215.

243 Professor Lamb noted:

[I] $t$ is clear that claims regarding the effects of early contact on mother-infant bonding are not well-supported by the empirical evidence. Most charitably, one could say that advocates of mother-infant bonding have yet to prove their case. More critically, one could say that early contact has no enduring effects on maternal attachment, but may sometimes have modest short-term effects on some mothers in some circumstances.

Lamb, supra note 219, at 294 (emphasis in original). For other research, see, e.g., Herbert, Sluckin \& Sluckin, supra note 219, at 209-12 (evidence fails to support critical-period hypothesis); Myers, Rejoinder, supra note 219, at 283-84 (sensitivity-period hypothesis not proven). 
gestational host. First, the very notion of postnatal bonding as a discrete phenomenon empirically is suspect. ${ }^{244}$ Parents typically love and nurture their children whether they are natural or adoptive parents. There appears to be nothing intrinsic to the biological parent-child relationship which does not similarly occur in an adoptive relationship. Moreover, difficulties in operationalizing the concept of bonding, together with the lack of evidence for the postnatal-sensitivity period, render the hypothesis an entity of dubious scientific status.

Second, even if the postnatal-bonding hypothesis is correct and new mothers experience a period of sensitivity shortly after birth which readies them for the task of mothering, this sensitivity would give the gestational host the morally superior claim to be a parent of the child if the process of bonding is experienced only by natural parents. If the process of bonding is experienced by all new parents, natural and adoptive, then the intended parents would possess the same propensity to bond with the child as does the birth mother. However, if the bonding process takes place only between the birth mother and the child, because bonding is brought about not by contact with the child but as a physical consequence of pregnancy itself, what would be the negative consequences of placing the child with someone other than the birth mother? There is little moral significance in the claim that relinquishment of the child precludes a bond that would have developed had the birth mother retained custody. The only real claim that can be marshalled on behalf of the birth mother is that breaking or precluding the postnatal bond $a b$ initio will result in some psychological harm to her. In essence, this reduces to a claim that compelled relinquishment of the child may have severe consequences for the psychological health of the birth mother. Whether or not this is true-and we shall turn to this question shortlythis issue is conceptually distinct from claims predicated upon the bonding process per se.

\section{The Best-Interests-of-the-Child Argument}

As noted previously, every state has recognized a presumption that it is in the best interests of the child to be placed with its natural parents. ${ }^{245}$ While the legal impetus for this presumption may be the parental-rights doctrine, ${ }^{246}$ some empirical evidence has linked several psychological problems among adopted children and adolescents to difficulties in the reproductive and early postnatal history of the child. ${ }^{247}$ In

\footnotetext{
244 See notes $242-43$ and accompanying text supra.

245 See notes 38-43 and accompanying text supra.

246 See notes 29-51 and accompanying text supra (discussing parental-rights doctrine).

247 See Isabella, Belskey \& von Eye, supra note 219, at 12.
} 
general, it is argued that separating the child from the birth mother may affect the child adversely in two ways. First, the child may incur irrevocable psychological harm because the parent and child fail to develop an emotional "bond." 248 These problems have been linked to the inability of both the mother to develop an attachment to the child and the child to develop a bond with its parents. Second, the child may experience psychological harm due to uncertainty regarding its biological heritage.

Throughout the 1960s and 1970s, researchers began to observe an apparent increase in the number of cases of child abuse suffered by prematurely born children. ${ }^{249} \mathrm{~A}$ developing body of evidence suggested that a bond must develop between parent and child during a critical period early in infancy-according to some, within twelve hours of birth. ${ }^{250}$ In considering what possible connection might exist between premature births and subsequent parental behavior toward the child, researchers hypothesized that vital medical treatment given to premature babies, requiring the separation of mother and infant, prevented the mother from bonding with the child. They concluded that the failure to bond resulted in a higher incidence of child abuse later in life. Thus, if a mother were precluded from interacting with her child soon after birth, there would be less likelihood that the mother-infant bond would develop.

A great deal of evidence also suggests that a symbiotic relationship between newborns and mothers develops throughout infancy. ${ }^{251}$ In particular, it appears that the level of maternal responsiveness to the behavioral and verbal signals of the child may affect the child's sense of attachment ${ }^{252}$ and the child's subsequent level of sociability. ${ }^{253}$ Thus, the bonding hypothesis posits that early maternal contact with a child is necessary to foster the mother's feelings for the child and, consequently, that development of the mother-to-infant bond is vital for the child's wellbeing. The crux of this first claim for the rights of the gestational host, then, is that the intended mother, not having experienced the mother-toinfant bond, may lack the nurturing qualities of the birth mother.

Insofar as this best-interests-of-the-child argument relies on the

248 See notes 219-44 and accompanying text supra (discussing bonding).

249 See T. Verney \& J. Kelly, The Secret Life of the Unborn Child 149-50 (1981).

250 See id.; Kennell \& Klaus, supra note 219, at 276-77 (authors, research pioneers who propounded bonding hypothesis, reevaluate evidence for sensitivity period, concluding that early mother-infant contact facilitates bonding but is not irreplaceable). But see Lamb, supra note 219 , at $488-92$ (arguing that sensitivity-period hypothesis is not well-founded).

251 See Isabella, Belsky \& von Eye, supra note 219, at 18 (study of one, three, and ninemonth-old infants concluding that secure attachment is fostered where mothers respond consistently and appropriately to infants' signals); Lewis \& Feiring, supra note 219, at 832, 836 (studying relationship between three-month-old infants and mothers and infants' later attachment behavior and sociability).

252 See Isabella, Belsky \& von Eye, supra note 219 , at 18.

253 See Lewis \& Fiering, supra note 219, at 836. 
mother-to-infant bonding hypothesis, it is susceptible to the empirical and philosophical criticisms raised above. ${ }^{254}$ Moreover, studies of attachment between adoptive mothers and children report no difference in the quality of attachment between adoptive and natural parent-child relationships. ${ }^{255}$ After reviewing the literature on the bonding issue, one group of researchers noted that early contact between mother and child has no provable long-term psychological consequences for the mother's feelings toward the child and, at best, only marginal short-term advantages. ${ }^{256}$ In light of these studies, the postnatal mother-to-infant bond cannot be an adequate basis upon which to ground an argument for the best interests of the child.

Alternatively, one might examine bonding from the standpoint of the child, i.e., the infant-to-mother bond. There is little doubt that the development of secure emotional ties between parent and child has fundamental and long-lasting significance. It is well-established that infants failing to form a bond with any adult are likely to lack the ability to form deep and enduring relationships later in life. ${ }^{257}$ One study found a strong correlation between insecurely attached infants and those who experience a higher level of nonmaternal care in the first year of life.258 Another study maintains that all infants who are placed for adoption after nine months of age have difficulties with a variety of "socioemotional" matters, including establishing certain kinds of relationships with others. ${ }^{259}$ Still other studies indicate that the quality of attachment in infancy may affect the IQ of the child ${ }^{260}$ and the development of the child's sense of self-identity, thereby affecting the child's ability to cope with various environments including schools. ${ }^{261}$

254 See text accompanying notes $221-44$ supra.

255 See, e.g., Singer, Brodzinsky \& Ramsay, Mother-Infant Attachment in Adoptive Families, 56 Child Dev. 1543, 1544, 1550 (1985) (claiming that while early mother-neonatal bonding is not necessary, adoption should take place in infancy to facilitate attachment).

256 See Lamb \& Hwang, supra note 219, at 21, 29.

257 See S. Fruiberg, Early Childhood Birthright: In Defense of Mothering $51-62$ (1977); Singer, Brodzinsky \& Ramsay, supra note 255 , at 1544.

258 See Belsky \& Rovine, supra note 219, at 16465.

259 See Yarrow \& Goodwin, The Immediate Impact of Separation: Reactions of Infants to a Change in Mother Figures, in The Competent Infant: Research and Commentary 1032, 1036-39 (L. Stone, H. Smith \& L. Murphy eds. 1973) (study of infants placed in adoption finds that, prior to three months, few infants react to changes in environment; between three and six months, number affected and severity of effect increased; and after nine months all infants demonstrated some adverse effect). But see Singer, Brodzinsky \& Ramsay, supra note 255, at 1549-50 (study of adopted infants finding no correlation between timing of adoption and mother-infant attachment). The latter study did not question the general empirical claim that the child must develop a strong relationship with an adult figure in order to mature properly. See id.

260 See van Ijzendoorn \& van Vliet-Visser, supra note 219, at 27.

261 See Singer, Brodzinsky \& Ramsay, supra note 255 , at 1544 . This study considered a 
These studies clearly indicate the importance to the child of developing a secure relationship with at least one parent figure early in childhood. There is absolutely no evidence, however, that the child must form this relationship with a biological parent. What is important is the psychology, not the biology, of the relationship. ${ }^{262}$ Thus, if a party, other than the gestational host, can render the same care and devotion as do most natural mothers, considerations of the child's best interests give the gestational host no inherently superior claim to the child. Moreover, it appears that younger children require less time to form ties with a new caretaker. ${ }^{263}$ Some have suggested that a very young infant may take as little as an hour to form a new bond with another person. ${ }^{264}$ Thus, even where a surrogate mother has formed a preliminary relationship with the child soon after birth, this factor alone fails to trump the claims of other participants in the procreative relationship.

The second genre of arguments favoring the gestational host and focusing upon the best interests of the child is founded not upon the prediction that the child will fail to form a bond with the nonbiologically related parent, but upon the argument that the child will suffer psychological harm as a result of the circumstances of birth. Thus, it is argued that the child will feel a sense of psychological "rootlessness" at not knowing her biological identity, ${ }^{265}$ or that a child will be disadvantaged by the "unnatural" procreative process that brought her into the world. 266

There are a number of responses to the charge that a child will suffer long-term psychological harm as a result of its uncertain biological identity. Insofar as this claim appears to address the uncertainty regarding the child's genetic heritage, this concern is unwarranted where the intended parents are the genetic parents of the child, as in gestational sur-

number of possible reasons why adopted children experience a much higher percentage of psychological problems. These include: (1) a more problematic prenatal and reproductive history, (2) complications associated with the social stigma surrounding adoption, (3) the nature of the transition from foster care to the adoptive home, (4) the effects of adoption placement beyond infancy, (5) difficulties associated with the adoption-revelation process, and (6) the confusion surrounding the adoptee's search for identity. See id. at 1543-44.

262 See J. Goldstein, A. Freud \& A. Solnitz, Beyond the Best Interests of the Child 105-11 (1973) (arguing that child's interests in psychological relationships with its caretaker parents should be protected in custody determination).

263 See Note, supra note 39, at 546-47 (discussing time factor in child's ability to break old bonds and form new relationships).

264 See T. Vernay \& J. Kelly, supra note 249, at 148.

265 See Robertson, Surrogate Mothers: Not So Novel After All, 13 Hastings Center Rep. 28,30 (1983) (concluding that child may experience rootlessness if unable to contact surrogate, but that similar situation is tolerated with adoptions).

266 Krimmel, for example, argues that because the surrogate conceives without wanting a child, the child suffers knowing that it was "conceived in order to be given away." See Krimmel, supra note 196, at 35 . 
rogacy. The claim also does not give the surrogate an advantage where neither she nor the intended parents are the genetic progenitors of the child, as where the sperm and eggs of anonymous donors are used. Moreover, even where the surrogate is the genetic progenitor, the child can receive information regarding her biological legacy precisely because surrogacy, unlike adoption, permits the intended parents to develop a complete medical record of the child's history and development. ${ }^{267}$

Finally, and perhaps most fundamentally, while the child may experience a natural curiosity regarding her parentage and biological legacy, there are problems with the prediction that this might affect the child's basic sense of self-identity throughout life. One commentator, for example, has argued that "[c]larity about [one's] origins is crucial for selfidentity, itself important for self-respect."268 This claim is predicated upon a troublesome view of personal identity, which implies that every adopted child is hopelessly insecure and devoid of self-respect. It appears to confuse the psychological notion of self-identity with the relatively more superficial knowledge of one's biological legacy. As such, this view is not only dubious empirically but also an atavistic throwback to the priority of blood ties over all else as a determinant of one's sense of self.

As for the claim that the child may experience psychological selfdoubt or alienation as a result of knowing that it was born through collaborative reproduction, it is not clear that this gives the gestational host any advantage over other participants in the procreative relationship. Indeed, since the surrogate initially has agreed to bear and relinquish the child, the child may feel less comfortable with her than with the intended parents. At any rate, this same charge was made against artificial insemination forty years ago. ${ }^{269}$ It is no more compelling now than it was then. In conclusion, notwithstanding the prevailing popular belief and the legal fiction that it is in the child's best interests to be raised by its natural mother, the best-interests argument provides little support for according parental rights in the gestational host above the claims of all others. We must, therefore, turn to another consideration raised by our initial dis-

267 See A. Overvold, supra note 195, at 92 (noting willingness of some couples to allow their children to meet surrogate who bore them). Alternatively, a file could be established containing the biological and medical history of the surrogate. This file could be constructed in a manner that would not identify the surrogate, if this is what the parties to the arrangement prefer. Cf. B. Lifton, Twice Born: Memoirs of an Adopted Daughter (1975) (providing personal account of adopted child's difficulties in finding natural parents).

268 Kass, Making Babies Revisited, 54 Pub. Interest 32, 47 (1979).

269 See J. Fletcher, supra note 3, at 126-27 (reviewing common arguments against artificial insemination and collaborative-reproductive techniques, including claim that child will experience psychic dislocation from its unusual origins). Fletcher rejects this claim by arguing that this issue is actually more problematic in adoption, where the child's original parents may not have wanted it, than in collaborative reproduction, where both parents consent to love and care for the child and desire to bring it into the world. See id. 
cussion of the bonding argument: whether the harm caused to the gestational mother by relinquishment of the child warrants granting her parental rights.

\section{The Relinquishment Argument}

One of the most poignant arguments favoring the right of the gestational host to be considered the mother of the child concerns the effects upon her of relinquishing the child. The effects of relinquishment on the birth mother in the case of adoption are well-documented. ${ }^{270}$ Indeed, there is evidence that new mothers experience a kind of separation anxiety when they are separated from their children even for relatively short periods of time.271 When the separation is permanent, the experience may take on extreme, even pathological proportions, including a deep sense of loss which pervades daily activities. ${ }^{272}$ Depression, anxiety, and a host of other emotional consequences may result. ${ }^{273}$ In one study, surrendering mothers reported recurring dreams of loss, fantasies involving rescue and reunion, heightened ecstasy in contemplation of the relationship with future children, and a greater than normal level of protectiveness toward their other children. ${ }^{274}$ These experiences were reported even by women who were not permitted to see their babies upon birth. ${ }^{275}$

Additional evidence indicates that the surrender of a child may remain a source of conflict and interpersonal difficulties for many years. ${ }^{276}$ In one study, $96 \%$ of all surrendering mothers reported that they had considered searching for the child while $65 \%$ actually had initiated a search. 277 Moreover, secondary infertility was higher among couples in which the woman previously had relinquished a child. ${ }^{278}$ Other reported

270 See Deykin, Campbell \& Patti, The Post-Adoption Experience of Surrendering Parents, 54 Am. J. Orthopsychiatry 271, 276-78 (1984) (women who surrender child for adoption perceive negative influence on marriage, fertility, and parenting); Millen \& Roll, Solomon's Mothers: A Special Case of Pathological Bereavement, 55 Am. J. Orthopsychiatry 411, 418 (1985) (experience of mother relinquishing child is similar to pathological mourning, including feelings of intense loss, panic, anger, and incompleteness); Rynearson, Relinquishment and its Maternal Complications, 139 Am. J. Psychiatry 338, 340 (1982) (relinquishment of child appears to be disjunctive event for women; subsequent maternal attachment is sought intensely).

271 See Hock, McBride \& Gnezda, Maternal Separation Anxiety: Mother-Infant Separation from the Maternal Perspective, 60 Child Dev. 793, 794 (1989) (confirming separation anxiety and finding that many factors, including mother's basic personality, genetically determined biases, and cultural background are relevant).

272 See Millen \& Roll, supra note 270, at 411-12 (discussing effects of relinquishment in extreme cases).

273 See id. at 413-17; Rynearson, supra note 270, at 338-39.

274 See Rynearson, supra note 270, at 339-40.

275 See id. at 339.

276 See Deykin, Campbell \& Patti, supra note 270, at 272.

277 See id. at 274.

278 Secondary infertility is infertility among couples who already have had children. See 
effects include marital disharmony (though the divorce rate among these couples was markedly lower) and both positive and negative child-bearing consequences. ${ }^{279}$ Finally, there is an increasing body of anecdotal evidence concerning relinquishment as a result of the experiences of Mary Beth Whitehead and other surrogates. ${ }^{280}$

In contrast to voluntary adoption, studies also suggest that the negative effects of relinquishment actually may be exacerbated by a compelled surrender of the child. One study found that parents were more likely to search for the child when external factors, such as family pressure, were instrumental in their decision to relinquish the child. ${ }^{281}$ By analogy, one might infer that the consequences of relinquishment may be even more difficult for surrogates required to surrender the child pursuant to a contractual promise than for those who relinquish the child in the absence of external legal coercion. Yet it may be at least as plausible to suggest that surrendering mothers in the adoption situation are more susceptible to the trauma of relinquishment than gestational hosts in the collaborativereproductive arrangement precisely because the adoptive mother is under no legal compulsion to surrender a child even where she informally has agreed to do so before birth. ${ }^{282}$ Indeed, it is likely that many surrendering mothers vacillate as to their decision for some time up to, and in some cases even after, the birth of the child. ${ }^{283}$ This wavering may aggravate feelings of loss once the decision is made to surrender the child. In short, expectations may influence feelings. If the postrelinquishment experience of birth mothers is at all related to their previous feelings regarding the child, then it is possible that women who do not expect to raise the child may be relatively less affected by relinquishment. This possibility is suggested by one poll of surrogate mothers in which only one in five reported that relinquishment was the most difficult aspect of the arrangement. ${ }^{284}$

OTA, Infertility, supra note 1 , at 50 . It is distinguished from primary infertility, where the couple has had no children. See id. The rate of secondary infertility among the study participants was $16 \%$ as compared with $6 \%$ of the general population. See id. at 276.

279 See id.

280 Mary Beth Whitehead was the surrogate in the Baby $M$ case. See In re Baby $M, 109$ N.J. 396, 537 A.2d 1227 (1988). For a narrative of her experiences immediately precipitated by her surrender of Baby M, see M. Whitehead \& L. Schwartz-Nobel, A Mother's Story: The Truth About the Baby M Case 17-37 (1989). For the experiences of another surrogate, see A. Overvold, supra note 195, at 33.

281 See Deykin, Campbell \& Patti, supra note 270, at 274.

282 Prebirth consent to adoption on the part of the birth mother is unenforceable in all fifty states. See Andrews, supra note 8, at 15-16.

283 If there were not such vacillation before birth and for some period afterward, there would be little need for laws rendering void prebirth consent to adoption as well as laws permitting the birth mother to revoke her consent for a period of time after relinquishment. See id. at 19 (discussing these statutes).

284 See A. Overvold, supra note 195 , at 130. 
The relinquishment argument is a vital component of the case for the priority of the gestational host. Nevertheless, more empirical evidence is necessary to evaluate the weight that should be accorded this claim and, in particular, the nature of postrelinquishment emotional effects upon the birth mother. We must determine whether these effects are intrinsic concomitants of the biological changes that occur during and after pregnancy, or whether they may be ameliorated by social influences and the birth mother's expectations regarding her role in the procreative arrangement.

Even if further research suggests that the harm of relinquishment is tangible, however, it is not clear that this effect should give the surrogate legal priority as the mother of the child. First, whatever harm redounds to the surrogate in the event of relinquishment must be weighed against a similar harm to the intended parents in the event that the surrogate does not turn over the child. Particularly where the intended parents are childless and infertile, the emotional significance of the loss of the child they expected to raise is undoubtedly great. ${ }^{285}$ Second, and perhaps most important, the surrogate's claims for legal priority resulting from the harms of relinquishment must be evaluated in the context of her earlier contractual agreement to relinquish the child. Parties to contracts often regret having entered into enforceable agreements. In some cases, they may be disadvantaged greatly by the agreement; but as long as the agreement is entered into voluntarily, 286 the argument that the surrogate now regrets having made this choice lacks the moral force it otherwise might have. ${ }^{287}$

\section{The Physical-Involvement Argument}

It has been suggested by a number of writers that the physical process of bearing the child in itself, independent of considerations of bonding and the effects of relinquishment, carries significant moral weight in determining who should be considered the parent. ${ }^{288}$ As one writer has stated:

And from the woman's point of view? We can use this man's sperm or that one's to have our children. With this or that man as father, our bellies will swell, life will stir, milk will flow. . . . For a man, what makes the child his is his seed. For women, what makes the child ours

285 See Kennell, Slayter \& Klaus, supra note 235.

286 See notes 294-303 and accompanying text infra (discussing exploitation and claim that surrogate's decision to enter into agreement is not voluntary).

287 See notes 284-85 and accompanying text supra (weighing relinquishment argument against claims of intended parents).

288 See, e.g., P. Chesler, Sacred Bond: The Legacy of Baby M 53-54 (1988) (comparing contribution of birth mother vis-á-vis that of sperm donor). 
is the nurturance, the work of our bodies. Wherever the sperm came from, it is in our bodies that our babies grow, and our physical presence and nurturance that make our babies ours. ${ }^{289}$

Inextricably intertwined with the notion of the birth mother's physical contribution are claims predicated upon the bonding hypothesis, the effects on the mother of relinquishment, and other related issues which have been considered in previous sections. This subsection attempts to abstract from this nest of issues an argument based simply upon the physical involvement of the gestational host.

The reality and extent of the physical involvement of the gestational host in the procreative process is obviously paramount. The birth mother risks sickness and inconvenience during pregnancy. She faces the certain prospect of painful labor. She even risks the small but qualitatively infinite possibility of death. Throughout all of this discomfort and uncertainty, it is her body which remains the cradle for the growing fetus. By comparison, the physical involvement of the sperm donor is de minimis. While the egg donor physically risks more 290 than the sperm donor, her level of physical involvement pales in comparison with that of the gestational host. Consequently, the argument postulates that this greater involvement should be the basis for recognizing the gestational host as the mother of the child.

Notwithstanding the obvious fact that the gestational host is the most important physical link in the procreative process, this argument encounters difficulties similar to those of the arguments for the priority of the genetic progenitors. ${ }^{291}$ The nature of this claim is that the gestational host has a kind of property right in the child. But, if so, then where she has entered a contract to act as gestational host for another, she has transferred this right. ${ }^{292}$ Even assuming she could have property rights in the child, the surrogate has no more of a claim to the "property" by virtue of this argument than a builder has in a house constructed for another. ${ }^{293}$

289 B. Katz-Rothman, supra note 189 , at 44 (emphasis in original).

290 The egg is taken by laparoscopy, a surgical procedure by which ova are removed from the ovaries of the woman. See OTA, Infertility, supra note 1, at 106.

291 See notes 206-17 and accompanying text supra (reviewing arguments favoring genetic progenitors on a "property rights" approach).

292 See notes 206-17 and accompanying text supra (discussing property-rights argument and transfer-of-rights argument in context of genetic progenitor). Where no contract exists, however, the surrogate's greater level of physical involvement should be entitled to great weight as evidence of the woman's intention to raise the child. See notes 308-20 and accompanying text infra (analyzing relevance of intention in procreative process).

293 At a presentation which I gave recently at IIT-Chicago Kent Law School, various participants took issue with this metaphor. "Children are not houses," it was stated, "nor are pregnant women housebuilders." I fully appreciate the relevance of this comment. Indeed, I am arguing that children are not the subject of property rights, though one's procreational 
If the argument of the gestational host's greater physical involvement is not a property claim, to what does it amount? One suspects that it is actually an argument predicated upon bonding, relinquishment, or the best interests of the child, or perhaps a combination of these other arguments. Excluding from the present argument claims based on the mother-infant bond, the effects of relinquishment, considerations of the child's best interests, and any theory predicated upon a kind of property analysis, virtually eliminates the argument of the greater physical involvement of the gestational host. Indeed, the argument appears to be a mere restatement of these other considerations.

\section{The Exploitation and Commodification Arguments}

Scholarly and legislative proposals defending the moral right of a woman to sell her gestational services have been the object of lively, if not vituperative, responses on the part of numerous writers, both in the legal literature ${ }^{294}$ and the academic press. ${ }^{295}$ The range and scope of these objections are too numerous and too deep to develop and to address systematically in this discussion. 296

Despite their sheer number and variation, however, these diverse arguments have two main recurring themes. The first, the "exploitation argument," posits that women who enter into surrogate agreements, as a general matter, somehow are unfree with respect to this decision. This moral assessment typically is predicated upon a matrix of social and economic factors which are held to predispose the prospective surrogate to her decision. In the words of one commentator:

When money animates the transfer of a human substance, the issue of exploitation arises. The danger is that the transferor is exploiting the

services are. My sole point here is that, even if the property metaphor were applicable to the transfer of a child, the gestational host would have no claim where the intended couple had compensated her.

294 See O'Brien, Commercial Conceptions: A Breeding Ground for Surrogacy, 65 N.C.L. Rev. 127 (1986); Olsen, The Family and the Market: A Study of Ideology and Legal Reform, 96 Harv. L. Rev. 1497 (1983); Radin, Market-Inalienability, 100 Harv. L. Rev. 1849 (1987); Wikler, Society's Response to the New Reproductive Technologies: The Feminist Perspectives, 59 S. Cal. L. Rev. 1043 (1986); Note, supra note 79; Note, Surrogate Mother Agreements: Contemporary Legal Aspects of a Biblical Notion, 16 U. Rich. L. Rev. 467 (1982); Note, supra note 2; Recent Developments, An Incomplete Picture: The Debate About Surrogate Motherhood, 8 Harv. Women's L.J. 231 (1985).

295 See Annas, Baby M: Babies (and Justice) for Sale, 17 Hastings Center Rep. 13 (1987); Annas, Contracts to Bear a Child: Compassion or Commercialism?, 11 Hastings Center Rep. 23 (1981); Ince, Inside the Surrogate Industry, in Test-Tube Women (R. Arditti ed. 1984); Krimmel, supra note 196; Merrick, Selling Reproductive Rights: Policy Issues in Surrogate Motherhood, 8 Pol. \& Life Sci. 161 (1990); Rothman, The Meanings of Choice in Reproductive Technology, in Test-Tube Women (R. Arditti ed. 1984); Woliver, Reproductive Technologies and Surrogacy: Policy Concerns for Women, 8 Pol. \& Life Sci. 185 (1990).

296 For a legal and philosophical defense of surrogacy, see Hill, supra note 181. 
desperate need of the transferee and that the transferee is exploiting the financial need of the transferor. . . . For some of the same reasons that organ donation is prohibited, commercial surrogacy should be prohibited. 297

Unlike the exploitation argument, which focuses upon whether the surrogate's decision was the product of causally determinative influences, the second general theme, the "commodification argument," focuses upon the object of the transfer. The commodification argument holds that certain intrinsic capacities or properties of the individual should not be alienable or commodified on the open market, and that a woman's reproductive ability is one such capacity. Professor Radin, a proponent of this view, has stated:

Market-inalienability [of surrogacy] might be grounded in a judgment that commodification of women's reproductive capacity is harmful for the identity aspect of their personhood and in a judgment that the closeness of paid surrogacy to baby-selling harms our self-conception too deeply. There is certainly the danger that women's attributes, such as height, eye color, race, intelligence, and athletic ability, will be monetized. Surrogates with "better" qualities will command higher prices by virtue of those qualities. ${ }^{298}$

The frequent allusions to organ donation, ${ }^{299}$ prostitution, ${ }^{300}$ and baby-selling, 301 are tempting and powerful analogues. These allusions run throughout the exploitation and commodification arguments. While this Article has undertaken an examination of the philosophical justification for these claims elsewhere, ${ }^{302}$ it is worth noting the basic difficulties with each of these two arguments.

The difficulties come in two forms, internal and external. The external difficulty, which will be discussed at the end of this subsection, is that these arguments are too powerful-they do not argue in favor of the gestational host. Rather, they militate against the very legitimacy of surrogacy as a legally permissible institution. The internal difficulties, by contrast, stem from flaws in the internal structure of these arguments. For example, proponents of the exploitation argument never elaborate a theory of exploitation. This failure sometimes manifests itself in the con-

297 O'Brien, supra note 294, at 142-43.

298 Radin, supra note 294, at 1932.

299 Barbara Katz-Rothman claims that "surrogacy is exactly the same as organ donation." See Levine, Whose Baby Is It?, Village Voice, Nov. 26, 1986, at 17.

300 One writer has equated the freedom to sell one's reproductive services with "the freedom to prostitute oneself." See G. Corea, supra note 223, at 227.

301 See Radin, supra note 294, at 1932.

302 See Hill, supra note 181, at 109-34 (examining coercion and exploitation as applied to surrogate arrangements); id. at $134-46$ (examining commodification argument). 
flation of the concepts of exploitation and coercion. ${ }^{303}$ More fundamentally, however, situations involving exploitation are not adequately distinguished from those which do not. For example, how is the situation of a woman from a lower-middle income family who enters a surrogate arrangement distinguished from the situation of this same woman who instead takes a job cleaning bathrooms in a bus station-assuming that this latter alternative is not itself exploitative? Let us assume that the compensation is at a similar rate and that the woman has similar alternative prospects. What distinguishes these two scenarios?. If the answer depends upon morally distinguishing the two activities-that cleaning bathroom floors is a morally permissible use of one's body while becoming a surrogate is not-then the respondent is confronted with a fundamental difficulty. The opponent of surrogacy is arguing that surrogacy is wrong because it is exploitative. She cannot then claim, when asked what makes surrogacy exploitative, that the two situations are distinguishable because surrogacy is wrong. This would constitute a blatantly circular argument. If surrogate arrangements are wrong because they are exploitative, then they cannot be exploitative because they are wrong.

However, if what distinguishes these two situations is that surrogacy involves the use of some intimate personal capacity which should not be the subject of barter, while bathroom cleaning does not, then the exploitation argument collapses into the commodification argument. Once the opponent of surrogacy makes this move, she relinquishes the claim that the decision to become a surrogate is, in some sense, unfree. Rather, it is wrong because it alienates a fundamental aspect of one's personhood. This reasoning, however, replaces the claim of exploitation with that of commodification.

The commodification argument similarly encounters a number of fundamental philosophical difficulties. The notion of commodification is functionally dependent upon drawing a distinction between a realm of personal capacities and properties which may be the subject of market alienation and those which may not. In one of the most careful and systematic elaborations of the commodification argument, Professor Radin states:

A better view of personhood should understand many kinds of particu-

303 Coercion could be said to occur whenever one's options are reduced by forces external to oneself. See A. Wertheimer, Coercion 40 (1987). Exploitation does not reduce options. Indeed, the exploitative situation typically occurs where an individual is given an additional choice which she cannot easily refuse. See id. at 39 (discussing exploitation of another's existing dilemma); Feinberg, Noncoercive Exploitation, in Paternalism 201 (R. Sartonius ed. 1983) (distinguishing coercion and exploitation by whether subject's options or interests are affected). 
lars—one's politics, work, religion, family, love, sexuality, friendships, altruism, experiences, wisdom, moral commitments, character, and personal attributes-as integral to the self. To understand any of these as monetizable or completely detachable from the person . . . is to do violence to our deepest understanding of what it is to be human. ${ }^{304}$

Notwithstanding her painstaking historical and philosophical analysis devoted to distinguishing "integral" or "intrinsic" from "extrinsic" personal attributes, Radin's view suffers from three fundamental flaws. First, no principle is presented by which essentially internal, noncommodifiable attributes may be distinguished from external, commodifiable attributes. There is little reason to believe that the attributes which $\mathrm{Ra}$ din cites-political action, work, love, sexuality, family, experience, and wisdom-are anything more than an ad hoc assortment of incongruous elements invested with varying degrees of importance in our culture. Moreover, without a principle distinguishing the internal and external, it is impossible to make future determinations as to which elements are basic to our sense of self.

Second, Radin admits that drawing the line between the internal and the external, the inalienable and the alienable, is ultimately a moral judgment. ${ }^{305}$ If one's reproductive capacity is an attribute which should not be subject to commodification, reproductive capacity will be deemed an essentially internal attribute. But this logic reverses the role of premise and conclusion. It attempts to determine whether a certain attribute is sufficiently internal to our personal identity so that we can render a moral conclusion about whether the attribute should be commodifiable. But Radin's analysis appears to begin with this moral assessment regarding the permissibility of commodifying an attribute. ${ }^{306}$ In essence, there would be no need to employ the commodification argument if we knew in advance that a particular capacity or attribute should not be commodified. Yet Radin's argument appears to require exactly this prior determination.

Finally, as a practical matter, we cannot sort neatly between inherently intrinsic and extrinsic attributes on the basis of the attribute itself. For example, while Radin suggests that personal attributes should not be commodifiable, ${ }^{307}$ they are routinely the subject of commodification. Indeed, it is difficult to imagine anything other than personal attributes which are commodified any time anyone is hired to do a job. The model uses her face and physique, the construction worker uses her physical

304 Radin, supra note 294, at 1905-06.

305 See id. at 1908.

306 See id. at 1859.

307 See id. at 1905-06. 
strength, and the professional utilizes her intelligence, character, and motivation-all attributes which go to the very heart of their personhoods. It is striking that those attributes which typically are denigrated as the more superficial or less intrinsic to the individual, such as physical beauty, eye color, and height, are the same attributes which so trouble the proponent of the commodification argument. Indeed, it would be more logical, on this view, to place attributes such as character, personality, and intelligence, which generally are thought to be central to our innermost being, beyond the reach of the market and to permit the commodification of physical attributes such as eye color and sexual attractiveness. On such a view, prostitution would be permitted while teaching philosophy would be placed outside the realm of the market.

In general, the exploitation and commodification arguments raise profound ethical questions which require careful attention and analysis. Unfortunately, this attention has been lacking, even in scholarly appeals to these arguments.

The arguments surveyed in this subsection take us somewhat far afield from the central focus of this piece. We have examined them briefly, however, because of their purported relevance to the parental status of the gestational host. Nevertheless, these arguments encounter a more fundamental difficulty for purposes of the present Article. Even if the exploitation and commodification arguments have some merit, they ultimately are not arguments favoring the parental priority of the gestational host. While they suggest that collaborative-reproductive arrangements should be regulated, even banned, they do not establish that the gestational host is the real "parent." In short, an argument against the social or ethical permissibility of surrogate arrangements is not necessarily an argument in favor of the moral priority of the surrogate as the mother of the child. If such arrangements are valid, the claim of the gestational host as the true mother of the child will have to depend upon other considerations.

\section{IV}

\section{The Claims of Intentionality}

The previous section considered the claims for the moral priority of the biological progenitors of the child, both the genetic sources and the gestational host. It is time now to consider briefly the possible claims favoring the priority of the intended parents. In this section, I pose the situation of the couple from the opening scenario. ${ }^{308}$ This is the case of the intended parents who have no biological connection with the child,

308 See text accompanying notes $19-20$ supra. 
but who have orchestrated the procreative relationship from the outset. They have brought together sperm and egg through in-vitro fertilization, and they have contracted for the services of a surrogate to bear the child they intend to raise. What reasons favor recognizing the intended parents as the procreators and, therefore, as the legal parents of the child?

Three arguments can be made for the moral priority of the intended parents. The first focuses upon the prima-facie importance of the intended parents in the procreative relationship. The second concerns the unfairness of permitting the surrogate to break the promise to relinquish the child. Finally, the third addresses important policy considerations in assuring the identity of the parents of the child from the time of conception. These arguments should trump the relatively weaker claims of either the gestational host ${ }^{309}$ or the biological progenitors. ${ }^{310}$

\section{A. The "But For"-Causation Argument}

Notwithstanding the competing claims of the various biological progenitors of the child, there is one essential fact favoring the moral and legal priority of the intended parents. The intended parents are, so to speak, the "first cause" of the procreative relationship; they are the ones who have engineered the birth of the child. Their desire and intention set into motion the entire process that begins with securing gamete donors and proceeds through the arrangement to have a woman bear the child.

The importance accorded to the intended parents' role as the first cause in the procreative relationship thus depends on adopting a nonbiologically based view of parenthood. What is essential to parenthood is not the biological tie between parent and child but the preconception intention to have a child, accompanied by undertaking whatever action is necessary to bring a child into the world. On this view, biological procreation is one way, albeit the most common one, to proceed in having a child. What is fundamental in rendering a biological progenitor a parent is not the biological tie itself, however, but the preconception intention and the preconception and postconception acts which the biological relation evinces.

It might be argued that this is a peculiar approach to the determination of parental status since it places a mental element, intention, over the tangible, biological tie. But just as mental state is relevant in other

309 See notes $219-44$ and accompanying text supra (maternal-bonding argument); notes 245 69 and accompanying text supra (best-interests-of-the-child argument); notes 270-87 and accompanying text supra (relinquishment argument); notes 288-93 and accompanying text supra (physical-involvement argument); notes 294-307 and accompanying text supra (exploitation/ commodification argument).

310 See notes 193-205 and accompanying text supra (genetic-identity argument); notes 20617 and accompanying text supra (property-rights argument). 
areas of the law, including contracts, torts, and criminal law, perhaps it is time that the determination of parental status similarly depend upon the preconception intent of the parties.311

Slightly recast, the first argument maintains that, while all of the players in the procreative arrangement are necessary in bringing a child into the world, the child would not have been born but for the efforts of the intended parents. The efforts of the biological progenitors are instrumental to the act of procreation, but the status of "parent" should go to the persons who constitute the "but for" cause of the child's birth.

It might be argued in response that the child would not have been born but for the assistance of the gamete donors and the gestational host. Thus, the position of the intended parents is not superior in this respect. Still, the position of the intended parents is distinct from that of the biological progenitors in two ways. First, the intended parents are the first cause, or the prime movers, of the procreative relationship. The others are participants only after the intention and actions of the intended parents to have a child. Second, while some gestational host and genetic progenitors are necessary to achieve the intention of the intended parents to have a child, no particular biological progenitors are necessary. Where one prospective biological contributor is not available, the couple can always seek the services of others. Thus, no one bur the intended parents stands in the relationship with the child of being the but for cause of the child's existence. This unique causal relationship with the child should afford the intended parents primary status as the parents of the child.

\section{B. The Contract Argument}

The second argument in defense of the priority of the intended parents focuses upon the preconception commitment of others, most notably, the gestational host, to refrain from claiming parental rights. The argument here is familiar: the gestational host and the genetic progenitors should be held to their original promises not to seek any form of parental rights in the child. There are two aspects to this argument, one deontological or rights-based and the other consequentialist. The deontological strain holds that people generally should be held to their promises simply because promise-keeping is a good in itself. The predicament of the intended parents is poignant precisely because the surrogate's promise is the very basis for her involvement in the procreative relationship in the first place. Absent a commitment on her part, the intended parents could seek the assistance of another. But where the

311 See Note, supra note 72, at 195 (family law traditionally has not relied upon mental elements). 
gestational host, or the genetic progenitor, for that matter, has gained access to the procreative relationship initiated by another, she should not be permitted the double injustice of reneging and, more importantly, retaining custody of the child.

The consequentialist strain of this argument emphasizes the reliance of the intended parents upon the promise of the other parties in the procreative relationship. The intended parents rely, both financially and emotionally, to their detriment on the promises of the biological progenitors and gestational host. They rely financially by purchasing the material essentials of child-rearing, including baby furniture, clothes, toys, and other accessories. They may even move or expand their home to accommodate the new arrival. If the promise of the other parties were not enforceable, the intended parents could not make these preparations without the possibility of losing their investment.

More importantly, the intended parents rely emotionally on the promises of the others to refrain from claiming parental rights in the child. They rely by preparing themselves psychologically for parenthood and all that it entails. They also rely emotionally to the extent that they have interacted with the surrogate and anticipated the birth of the child. ${ }^{312}$

It has been argued that the gestational host, in particular, should not be held to her promise because of the unpredictable nature of the development of feelings for the child while she is pregnant. ${ }^{313}$ Elsewhere, I have proposed guidelines to mitigate this possibility. ${ }^{314}$ At any rate, whether the claims of the gestational host should be honored above the claims of the intended parents depends upon a weighing of the broader issues raised by the bonding hypothesis and the compelled-relinquishment argument. 315

312 Even here, the intended parents' reliance cannot be absolute. The surrogate retains her constitutional rights to obtain an abortion. See text accompanying notes 165-81 supra (discussing surrogate's right of privacy). Nevertheless, particularly during the last trimester, after the point of viability, the surrogate's commitment to having the child will be clear. Reliance on the part of the intended parents after this point would be justified.

313 See Suh, supra note 9, at 363.

314 I have proposed a rule that only women who previously have had children should be permitted to become surrogates. See Hill, supra note 181 , at 361 . This rule would enable the prospective gestational host to predict more adequately her feelings during pregnancy. Also, the process of psychological screening of applicants should be made more rigid to weed out those who would be expected to have a particularly difficult time with relinquishment. See id. at 362. Finally, surrogate contracts should receive judicial screening and approval. See id. at 366. This judicial oversight would require the surrogate to affirm publicly her promise and intention to relinquish the child. This requirement might reduce further the number of surrogates who are uncertain about relinquishing the child.

315 See notes $219-44$ and accompanying text supra (discussing bonding hypothesis); notes 270-87 and accompanying text supra (discussing compelled-relinquishment argument); conclusion infra (discussing relative weights given to these claims). 


\section{The Avoidance-of-Uncertainty Argument}

Where the identity of the parents is not determined at the time of conception, all parties are affected adversely. If the gestational host or the genetic progenitors of the child legally are permitted to claim parental rights in the child, contrary to their earlier promises, then the identity of the child's parents will remain unanswered as litigation may drag on for years after the birth of the child. The ultimate solution may render all concerned parties-the intended parents, the biological progenitors, and the child-victims of the uncertainty.

If there is any truth to the notion that the feelings of the gestational host toward the child are influenced by her expectation of raising the child, then the surrogate may develop proprietary feelings toward the child because she retains the possibility of challenging the claims of the intended parents. However, if this prospect is not open to her, the gestational host will be less likely to entertain such sentiments toward the child. Of course, this claim is dependent upon the empirical observation that the development of maternal feelings is influenced by social factors such as the expectation of raising the child.

From the standpoint of the intended parents, I have argued already that it is important that they be able to rely on their expected status as parents in making preparations, both financial and emotional, for the arrival of the child. ${ }^{316}$ Where the prospect remains open that their claims may be subordinated to those of one of the biological progenitors, the logistic and emotional preparation by expectant parents may be inhibited, rendering the transition to parenthood more difficult. ${ }^{317}$

Finally, the uncertainty regarding the identity of the parents takes its most compelling form from the standpoint of the child. In cases where litigation over parental rights takes years, the child may grow up with uncertainty regarding the identity of her parents. This uncertainty only is aggravated by the likely solution to the conflict-a decision dividing the child's time among joint custodians or, as in Baby $M$, a disposition which grants custody to one couple and visitation privileges to another. ${ }^{318}$ Permitting challenges to the parental status of the intended parents virtually ensures that the child will grow up in the functional equivalent of a broken home. ${ }^{319}$ For all of these reasons, the identity of

316 See text accompanying notes $312-15$ supra.

317 Studies indicate that paternal anxiety is inversely related to the extent of participation on the part of a new father. See Fein, supra note 219, at 341. In other words, once the role of the father is established, he is more likely to feel a part of the child-rearing process with a concomitant reduction of psychological anxiety. This phenomenon might be analogous to that which the expectant intended parents undergo.

318 See In re Baby M, 109 N.J. 396, 466, 537 A.2d 1227, 1263 (1988).

319 Of course, a rule providing that the intended parents will take the child unless the surro- 
the parents should be determinate $a b$ initio from the time of conception. ${ }^{320}$

\section{CONCLUSION}

With the expanding popularity of the various collaborative-reproductive techniques and arrangements, including surrogate parenting, it is increasingly imperative to settle the question of parental status in collaborative-reproduction arrangements. Having considered the arguments in defense of the claims of the genetic progenitors, the gestational host, and the intended parents, it is clear why the intended parents should be considered the "parents" of the child born of the reproductive arrangement in the opening scenario.

This Article has argued that the genetic relationship, in itself, should be accorded very little moral weight in the determination of parental status. Claims based on the biological similarity of genetic progenitor and child and those predicated on a kind of quasi-property right in the child simply do not withstand sustained scrutiny. Thus, though the genetic tie historically has been accorded great significance, the genetic link per se places the genetic progenitor in the least-compelling position of all parties in the procreative relationship.

What can be said of the claims of the gestational host? The genre of arguments which predicates the surrogate's priority as parent upon the best interests of the child are not convincing. Similarly, the claims based upon her greater physical involvement in the procreative process, as well as those based upon a number of social and ethical concerns, are of little moral force. At best, the social and ethical arguments suggest only that certain forms of collaborative reproduction, particularly surrogate arrangements, should be regulated or prohibited altogether. They do not speak to the moral priority of the gestational host.

This leaves the arguments founded upon the bonding hypothesis and the harms predicted to result from compelled relinquishment of the child. As we have seen, empirical support for the postnatal mother-to-

gate changes her mind, in which case she will be awarded full parental rights, would eliminate this uncertainty from the standpoint of the child. The difficulty with this rule, however, is that with traditional surrogacy, where the intended father is also the sperm donor, parental rights would be split between him and the surrogate. The child would continue to live a life divided between two families. This outcome would be the case unless the proposed rule not only gave the surrogate full rights as mother, but also cut off all rights possessed by the sperm donor/ intended father.

320 The gestation host should be permitted to renounce the contract at any time before conception has occurred. Furthermore, because the designation of parental status in the intended parents does not entail that the gestational host forfeits her constitutional privacy rights, she will retain the right to have an abortion. See notes $165-81$ and accompanying text supra (discussing distinction between right of privacy and right of procreation). 
infant bond is equivocal at best. Indeed, a preponderance of the more recent evidence contradicts the hypothesis. Nonetheless, it would be preposterous to argue categorically that the gestational host harbors no feelings for the child at birth. The gestational host interacts intimately and directly with the fetus with increasing frequency from the time of quickening. Thus, in some cases, the surrogate possesses strong attachment to the child by the time of birth. But even if these feelings amount to a prenatal mother-to-infant bond, they fail to trump the claims of others. The bonding hypothesis is significant only to the extent that it suggests that it will be more difficult for the gestational host to relinquish the child than for the intended parents to give up their dream of parenting the child. Thus, it appears that the bulk of the claims for the priority of the gestational host boils down to the deleterious consequences of relinquishment, exacerbated as this may be by the lingering effects of the prenatal bond.

It is not likely that the relinquishment argument itself will be sufficient to accord the gestational host legal recognition as the child's mother. Ultimately, the weight of the relinquishment argument will depend in part upon further empirical assessment of the harms of relinquishment. Minimally, however, the argument for the priority of the gestational host has been overstated. Unexamined assertions predicated upon the best interests of the child, the bonding hypothesis, and the greater physical involvement of the gestational host in bearing the child, among others, have been the result of both a mischaracterization of the empirical evidence and a superficial assessment of the moral weight of this evidence.

This Article concludes that the balance of equities favors the claims of the intended parents over those of the gestational host. The moral significance of the intended parents' role as prime movers in the procreative relationship, the preconception promise of the biological progenitors not to claim rights in the child, and the relative importance of having the identity of the parents determined from conception onward outweigh the potential harm to the gestational host in compelled relinquishment. This conclusion, of course, will not be well-regarded in all quarters. An important reason for this skepticism is that a fundamentally biological conception of parenthood is ingrained deeply in the ethos of our culture. It continues to influence our most profound intuitions concerning the nature of parenthood and parental rights.

Nevertheless, the biological conception does not square with a number of other, equally deep, intuitions. It is not consistent with the modern understanding that parenthood is as much a social, psychologi$\mathrm{cal}$, and intentional status as it is a biological one. It also is inconsistent with the sentiment that persons are not invariably and irrevocably 
predisposed to a role in life-even that of parenthood-by virtue of the inexorable workings of biology. Finally, and most fundamentally, the biological conception of parenthood cannot be reconciled with the belief that other moral considerations sometimes may override claims predicated upon the biological relationship. In essence, the claims of biology cannot be deemed to trump invariably the moral claims of those who entertain no biological connection with the child. 


\section{NEW YORK UNIVERSITY \\ LAW REVIEW}

\section{MEMBERS OF THE LAW REVIEW 1990-1991}

\section{Managing Editor \\ JAMES S. DEGRAW \\ Senior Articles Editor \\ MichaEL W. DOWDLE}

\section{Articles Edirors}

STUART C. BERMAN

LAURENCE R. HELFER

STOWELL R.R. KELNER

DONNA H. LEE

SuJA A. Thomas

MARK W. ECKENWILER

LisA E. Gross

JORDAN I. BAILOWITZ

Terence G. Clark

ANNE L. EU

\author{
ANAND AGNESHWAR \\ ROSE AUSLANDER \\ DAVID BARRES \\ DAvid BAXIEY \\ Mary Ellen Benz \\ MARY ANN K. BosaCK \\ ELLEN BRESLER \\ SAMUEL W. BuelL \\ Juan Pablo Cappello \\ KYUNG-JOON CHOI \\ Joseph V. DE MARCo \\ Giuliana H. DunhaM \\ Carlton E. EINSEl III \\ Kieran J. Fallon \\ JAMES B. FuQUA
}

Business Manager LAURA L. SMITH
Editor-in-Chief

JOHN C.P. GOLDBERG

\author{
Executive Editors \\ CAITLIN E. BORGMANN \\ LUISA KAYE
}

Senior Note and Comment Editor

BENJAMIN ZIPURSKY
Review and Essay Editor ElizabeTh S. JAHNCKE

Developments Editor

Peter G. Neiman

Associate Editors JORGE U. JUANTORENA

Senior Editorial Staff

Paul B. Hudson

HARRY H.W. KIM

\section{Editorial Staff}

JoNATHAN GALST

Michael. J. GERGEN

Megan R. Golden

ROBIN L. GOLOMB

DEBORAH GORDON

Christopher R. HiLl

Nina R. HUFFMAN

AIMEE C. JIMENEZ

EMILIO JIMENEZ

HANG C. LEe

MARCI A. LERNer

RICHARD B. LEVY

JOAN J. LEWIS

KAREN L. Miller

Daniel R. Milstein
Michael D. Paranzino Michael C. RosensteIN

BRAD J. RICHTER JAMES STEINTHAL Young J. YoO

Boaz S. Morag BRIAN G. MURPHY JOHN J. O'BRIEN DOMINIQUE P. PARKER SHARON PERLEY PAUL ROCKLIN

HowARD L. SIEgeL. WILLIAM C. SILVERMAN Lisa Simotas STEPHEN M. SINAIKo JEFFREY S. SLOAN KENNETH B. SQUIRE NAIKANg TSAO JAMIE WILSON

THEA A. WINARSKY

Technical Assistant

Allan G. MacDonald

Faculty Advisor

LAWRENCE G. SAGER 